\title{
Distributed Acoustic Sensing for Near Surface Imaging from \\ Submarine Telecommunication Cable: Case Study in the Trondheim Fjord
}

\author{
Kittinat Taweesintananon*, Martin Landrø*, Jan Kristoffer Brenne ${ }^{\dagger}$ and Aksel \\ Haukanes $^{\dagger}$ \\ * Department of Electronic Systems, Faculty of Information Technology and Electrical \\ Engineering, NTNU - Norwegian University of Science and Technology, Trondheim, \\ Norway.E-mail: kittinat.taweesintananon@ntnu.no; martin.landro@ntnu.no. \\ ${ }^{\dagger}$ Alcatel Submarine Networks Norway AS, Vestre Rosten 77, Tiller, Norway. E-mail: \\ jan.kristoffer.brenne@asn.com; aksel.haukanes@asn.com.
}

(May 13, 2021)

This non-peer reviewed preprint submitted to EarthArXiv was submitted to Geophysics journal for peer review. Running head: DAS for Near Surface Imaging

\begin{abstract}
Distributed acoustic sensing (DAS) transforms submarine telecommunication cables into densely sampled seismic receivers. To demonstrate DAS applications for seismic imaging, we use an optical cable on the seafloor in the Trondheim Fjord, Norway, to record seismic data generated by a controlled seismic source. The data are simultaneously recorded by a towed hydrophone array and the fiber optic cable. Following our data processing methods, we can produce seismic images of the seafloor and underlying geological structures from both the hydrophone array data and the DAS data. We find that the DAS data and the
\end{abstract}


hydrophone data have a comparable signal-to-noise ratio. Moreover, DAS images can be improved by using a seismic source that has sufficiently large energy within the frequency range matching the spatial resolution of DAS. The temporal resolution of the DAS images can be improved by minimizing the crossline offset between seismic sources and the DAS cable. The seismic images from DAS can be obtained to support geohazard analysis and various subsurface exploration activities. 


\section{INTRODUCTION}

Near surface seismic imaging is essential for investigating shallow gas, weak layers, faults, and other potential subsurface geological hazards. These elements can adversely affect offshore activities such as drilling operations, offshore platform and wind farm construction, and pipeline surveys. The oil and gas industry uses near surface information to improve the images of deeper structures and to reduce risks in exploration and production. To precisely investigate near surface irregularities, ultrahigh-resolution reflection seismic data acquisition and processing techniques have been developed (Monrigal et al., 2017).

Marine seismic data can be recorded either by hydrophone streamers towed behind sailing vessels or by seismic receivers deployed on the seafloor. Seismic reflections from near surface structures are mostly available at the receivers with short offsets from the source. To acquire near offset seismic data, we may place the source over the streamer spread, which requires separated vessels for sources and streamers (Vinje et al., 2017). Another solution is to minimize the distance between sources and dense streamers (Monrigal et al., 2017; Thomas et al., 2012). However, it requires shortening the streamer length for operation safety. The lack of far offset information consequently causes high uncertainty to velocity model building. On the other hand, short offsets and dense receiver spacing in streamers result in high stacking fold and small imaging bins for near surface imaging. Hence, when combined with high-frequency seismic sources, the effective vertical and spatial resolution becomes significantly higher than conventional broadband seismic data.

Seabed seismic acquisition has been growing in the marine seismic market for its advantages over towed streamer techniques. The physics of seabed seismic acquisition is better than towed streamer acquisition for the following reasons (Landrø and Amundsen, 2018). 
First, its receivers are placed on the seafloor, which has lower noise level than towed streamers. Second, it has no limits to the offsets and azimuths between sources and receivers. Long offsets and wide azimuths of the data can significantly improve the accuracy of seismic velocity models and the seismic illumination of complex structures. Third, it records both pressure wave and shear wave, so it can provide high quality images even in the areas with strong amplitude absorption in the presence of gas. Last, it has fewer impacts from the sea surface ghosts that limit the frequency bandwidth of the seismic data and, hence, the image resolution.

Ocean bottom cable and ocean bottom node are common recording systems in the seabed seismic market. The node system is a blind recording system, as it acquires data internally and exports the data later. In addition, nodes are powered by internal batteries which requires an effective power management plan during the operation. In contrast, data recorded by ocean bottom cables can be visible on a real-time basis. Traditional cable systems for seabed seismic acquisition are bulky electronic networks. However, the electrical cables can be replaced with fiber optic sensing cables, while the recording performance is maintained (Langhammer et al., 2010). Besides the real-time monitoring feature, a key advantage of the fiber optic sensing systems is that no electronic and electrical power components are required at the sensing points giving unsurpassed reliability for permanently installed sensing systems.

Distributed Acoustic Sensing (DAS) is an emerging technology that utilizes fiber optic cables for acoustic measurements. It has been applied in military defense, engineering structure monitoring and petroleum exploration (Wang et al., 2019). DAS transforms a fiber optic cable into a densely sampled sensor array. The cable itself is the sensing element without additional transducers in the optical path. Laser pulses transmitted into the fiber 
are continuously reflected to the interrogator due to the Rayleigh backscattering process inherent to all optical fibers. The phase of the backscattered light is reconstructed within the interrogator typically for each meter of the fiber. As the phase of the reflected optical light is proportional to the strain of the fiber, the distributed strain modulation across a fiber segment (termed the gauge length) can be computed. Therefore, DAS can sense seismic waves that modulate the extensional strain of the fiber segment (Hartog, 2017). Its seismic response is somewhat similar to the inline component of conventional point accelerometers, in which it is mainly sensitive to seismic wave propagating creating strain along the cable direction (Papp et al., 2017).

Over the past decade, many applications of DAS have been studied and introduced to applied seismology community and petroleum industry. Daley et al. (2013) demonstrated a field test of DAS seismic acquisition of borehole seismic data and land surface seismic data. Additionally, Dean et al. (2016) discussed its applications to marine seismic acquisition. On the other hand, Lumens (2014) studied various applications of DAS in oil and gas wells. Besides borehole applications, DAS can be applied in the fiber optic telecommunication cables deployed on the ground and seafloor. Many case studies of DAS using onshore telecommunication infrastructure have been carried for passive seismic monitoring such as earthquake detection, near surface soil study, ambient noise analysis, urban traffic monitoring, glacier flow monitoring, and other seismic activities (Ajo-Franklin et al., 2015, 2019; Biondi et al., 2017; Dou et al., 2017; Fang et al., 2020; Fernández-Ruiz et al., 2020; Kowarik et al., 2020; Lindsey et al., 2020; Martin et al., 2017, 2018; Walter et al., 2020; Yu et al., 2019; Zhu et al., 2020). Moreover, it can monitor seismic wave from controlled sources to study and prevent onshore geohazards (Ajo-Franklin et al., 2017). In addition to onshore environments, DAS in underwater telecommunication fibers can detect oceanic 
wave, micro-seismic noise, earthquakes, and near surface geological structures and faults (Lindsey et al., 2019; Sladen et al., 2019; Williams et al., 2019).

Nevertheless, applications of DAS to generate interpretable seismic images of the subsurface geological structures have not been widely presented. It is important to acquire multifold and diverse examples to show whether DAS can be used for near surface imaging and how to improve its performance. These statements could be proven by comparing the images from DAS with those from other conventional seismic methods. The validity of DAS seismic acquisition could be a game changer and a useful complement to the conventional seabed seismic market.

This article demonstrates seabed seismic applications of DAS for near surface seismic imaging. The experiment is done by utilizing an existing submarine telecommunication cable in Trondheim Fjord, Norway. We firstly use DAS to record seismic waves generated from a bubble gun towed at $1 \mathrm{~m}$ below the sea surface. Then, we analyze and process the data to produce the seismic images of the seafloor and its underlying geological structures. The results are, then, compared to the seismic data simultaneously recorded by a conventional towed hydrophone array $(7 \mathrm{~m} \mathrm{long})$. Finally, we discuss the requirements and limitation of DAS to seabed seismic acquisition and subsurface imaging.

\section{EXPERIMENTAL SETUP AND DATA ACQUISITION}

We conduct a marine seismic survey in Trondheim Fjord using NTNU's research vessel, $\mathrm{R} / \mathrm{V}$ Gunnerus, as shown in Figure 1. One single marine seismic source and one singlechannel hydrophone streamer are towed behind the vessel. The seismic data from the streamer are recorded by HMS-620 Bubble Gun Recording System through Subbottom 
Sonar Interface Software from National Instrument. Simultaneously, we record the seismic data using the OptoDAS interrogator, which has been developed by Alcatel Submarine Networks, connected to a dark fiber in a seafloor telecommunication cable. The DAS data are continuously recorded throughout the survey program. The map of the source line and DAS cable is shown in Figure 2.

The seismic recording system of the vessel consists of HMS-620 Bubble Pulser electric seismic source and a short hydrophone streamer with $7 \mathrm{~m}$ of a single-channel array comprising 24 elements. The source and streamer are towed approximately $20 \mathrm{~m}$ behind the vessel's reference position, and they are $10 \mathrm{~m}$ apart from each other perpendicular to the sail line. The source and streamer depths are approximately $1 \mathrm{~m}$ below the sea surface. The recording time sampling interval is $0.25 \mathrm{~ms}$, and the maximum recording time for each shot is $266.25 \mathrm{~ms}$. The recording start time is synchronized with the gun firing time. The layout diagram of the source and streamer towed behind the vessel is shown in Figure 3 .

The acoustic source energy is approximately $50 \mathrm{~J}$, which is equivalent to $200 \mathrm{~dB}$ relative to the reference pressure $1 \mu \mathrm{Pa}$ at reference distance $1 \mathrm{~m}$. The frequency bandwidth ranges from $350-1000 \mathrm{~Hz}$ at $10 \mathrm{~dB}$ down, where the dominant frequency is about $600 \mathrm{~Hz}$. The shot time interval, namely gun firing time interval, is set to $267.75 \mathrm{~ms}$ in the system. We will see later that the actual shot time interval is slightly deviated from this value due to instrument delay. The vessel is navigated to be as close to the DAS cable as possible. The vessel's speed is 2 knots in average to acquire high-density seismic data with minimal noise from the vessel's propulsion. Hence, the average shotpoint interval is approximately $0.275 \mathrm{~m}$.

The DAS recording system is independent of the vessel's equipment. The DAS data are continuously recorded using $0.44 \mathrm{~ms}$ time sampling interval throughout the survey. The 
channel spacing is $2.04224 \mathrm{~m}$, while the gauge length is $4.0852 \mathrm{~m}$.

\section{DATA CHARACTERISTICS}

The seismic data recorded by the single-channel streamer can be displayed as a common channel gather as shown in Figure 4. The data are formed by summing a linear array of 24 hydrophone elements within $7 \mathrm{~m}$ streamer length into one single recording channel. The data contain both the direct wave and reflected waves, as highlighted by the black arrows in the figure. The direct wave in the streamer data does not propagate through the subsurface. Therefore, only the reflected waves are used to image the seafloor and subsurface geological structures.

On the other hand, the DAS data are continuously recorded. Each seismic trace corresponds to an individual recording channel resulting from the strain demodulation across a fiber segment of $4 \mathrm{~m}$ gauge length, where the channel spacing is $2 \mathrm{~m}$. To derive proper shot records for further analysis, every continuously recorded seismic trace is edited and broken into several shorter traces associated with different shot numbers. This trace editing requires that the precise gun firing time interval is known. In this experiment, we find that the actual gun firing time interval is $267.67 \mathrm{~ms}$. This value slightly differs from the source equipment's setting (267.75 ms) due to minor instrument errors.

Typical seismic profiles derived from DAS contain obvious hyperbolic events generated by our seismic sources. The data also contain low-frequency signals, as shown in Figure 5(a), that might include source-generated surface waves. However, our study focuses on the direct wave and reflected waves, since the other source-generated waves like surface waves are incomparable to streamer data. A simple band-pass filter $(160-600 \mathrm{~Hz})$ can attenuate most 
of the undesired low-frequency contents and reveal the seismic signal directly propagating from the source as shown in Figure 5(b). The direct wave is obviously presented in at least 40 recording channels (approximately $80 \mathrm{~m}$ of the cable) as highlighted by the yellow arrow in Figure 5(b). We observe that reflected waves are hardly observed in shot profiles even after filtering. However, they can be enhanced and observable after supergathering as discussed later. Since the DAS receivers are trenched into the seafloor, the direct wave can be used to image the seafloor topography. The waves reflected from the subsurface below the seafloor are used to image the subsurface geological structures.

\section{METHODS}

As a key reference, the seismic image of the seafloor and the subsurface from the singlechannel streamer data is obtained through the following processes:

1. Apply static time shift to redatum the source and receiver to the sea surface.

2. Apply Normal Move Out (NMO) correction to correct the traveltime from arbitrary offsets to zero offset, where the source and receiver are virtually at the same position. To be compared with the DAS data set, the NMO velocity from DAS data processing is used.

3. Mute the undesired direct wave.

4. Apply zero-offset time migration using the NMO velocity.

We also resample the streamer seismic data from $0.25 \mathrm{~ms}$ to $0.44 \mathrm{~ms}$ to be matched with the time sampling interval of the DAS data. 


\section{DAS seismic recording}

In contrast to streamer data, DAS data are continuously recorded along the cable with much more recording channels. To extract a shot profile from this continuously recorded data, we need to know the precise gun firing time of the source. However, synchronous sampling of the DAS and streamer recording systems were not utilized in our experiment. Therefore, we use the Coordinated Universal Time (UTC) time stamps of the gun firing from the recorded streamer data in SEG-Y format to tailor the continuously recorded DAS data into several shot profiles. However, the precision of the gun firing time shown in SEG-Y header is $1 \mathrm{~s}$. In contrast, the recording time interval of the DAS data is $0.44 \mathrm{~ms}$. Therefore, it is uncertain to define the exact time sample in the DAS data when the gun is fired from the given time stamp with lower precision. To overcome this challenge, we propose a data-driven method by estimating the start time of each shot record from the corresponding first arrival time in the DAS data.

Assuming the DAS receivers are on the seafloor, the first arrival event at near offsets is the direct wave propagating from the source to DAS receivers as shown in Figure 6. Given time picks of the first arrival at the inline offset of $h_{x}=0$ and any $h_{x}$, we can estimate the source-to-cable distance $(d)$ and, then, the start UTC time of a DAS shot record $\left(t_{0}\right)$ using the following expressions (see Appendix A for derivation):

$$
d=\frac{v}{2 \Delta \tau}\left(\frac{h_{x}^{2}}{v^{2}}-(\Delta \tau)^{2}\right)
$$

and

$$
t_{0}=t_{\left\{h_{x}=0\right\}}-\tau_{\left\{h_{x}=0\right\}}=t_{\left\{h_{x}=0\right\}}-\frac{d}{v},
$$

where $v$ is the $\mathrm{P}$-wave velocity in the sea water, $t$ is the picked UTC time that the direct wave arrives to a receiver on the DAS cable, $\tau$ is the traveltime for the wave that propagates 
directly from the source to a receiver, and $\Delta \tau$ is the difference between $\tau$ at $h_{x}=0$ and $\tau$ at any $h_{x}$. That is, $\Delta \tau=\tau_{\left\{h_{x}\right\}}-\tau_{\left\{h_{x}=0\right\}}$, where $\tau_{\left\{h_{x}=0\right\}}=\frac{d}{v}$ by definition. In this study, we assume the velocity in water to be constant at $1490 \mathrm{~m} / \mathrm{s}$. Using the expressions above, we can derive the start UTC time of every shot and construct individual shot profiles of DAS.

It should be noted that equation 1 can determine the distance $(d)$ between source and DAS cable, even if no information of the source position is given. Consequently, equation 2 requires no source parameters to determine the gun firing time. Moreover, given the water depth $(z)$ of a receiver, we can estimate the crossline offset $\left(h_{y}\right)$ using the expression below,

$$
h_{y}=\sqrt{d^{2}-z^{2}}
$$

Therefore, with sufficient constraints from recording geometry, it is possible to derive the position and time of sources from DAS data by analyzing the traveltime of the direct wave. Then, we may utilize the signals from unknown sources for subsurface imaging, which should be further studied. Nevertheless, this article will focus on the DAS application using controlled seismic sources.

Given shot profiles recorded by DAS, we do preconditioning steps to enhance the signalto-noise ratio $(\mathrm{S} / \mathrm{N})$ of the data followed by imaging steps. Since the receivers are located at the seafloor, the seismic images of the seafloor and its underlying subsurface structures are generated from different seismic events. The seafloor image, i.e. water depth topography, can be derived from the direct wave from source to the receivers on the seafloor. On the other hand, the structural image below the seafloor can be derived from the corresponding seismic reflections. Hence, we require two different imaging methods to generate the complete 
subsurface image comprising both seafloor topography and its underlying structures. The processing sequence for DAS data is summarized in Appendix B.

\section{Normal Move Out (NMO) correction for direct wave}

The direct wave from the source to the DAS receivers on the seafloor is illustrated in Figure 7. The NMO traveltime correction $\left(\Delta t_{\mathrm{NMO} \text {,direct }}\right)$ is to map the traveltime $\left(t_{\text {direct }}\right)$ of the direct wave event to $t_{z}$, which is the one-way traveltime for the vertical propagation distance of $z$. The NMO correction for the direct wave is

$$
\Delta t_{\mathrm{NMO}, \text { direct }} \equiv t_{\text {direct }}-t_{z}=\sqrt{t_{z}^{2}+\frac{h^{2}}{v^{2}}}-t_{z}
$$

where $t_{\text {direct }}=\sqrt{t_{z}^{2}+\frac{h^{2}}{v^{2}}}, h \equiv \sqrt{h_{x}^{2}+h_{y}^{2}}, h_{y}=\sqrt{d^{2}-z^{2}}$, and $z$ is the known water depth for the central receiver $\left(h_{x}=0\right)$. Thus, the correction will produce the one-way-time zero-offset seismic gather where the source is virtually right above the central receiver. Multiplying the time axis by two will convert the gather into two-way time to be comparable with the seismic reflection data from the streamer.

In practice, we redatum the source and receivers to be at the sea surface prior to NMO correction to output the two-way traveltime seismic image. That is, the receiver static correction of $t_{z}$ is added to the traveltime of the wave path in Figure 7(a). Then, the traveltime of the shot profile after redatuming to the sea surface is defined as:

$$
T_{\text {direct }} \equiv t_{\text {direct }}+t_{z}
$$

where $t_{\text {direct }}$ is the one-way traveltime of direct wave from source to a receiver. Here, the NMO correction is to map the redatumed traveltime $T_{\text {direct }}$ into the two-way traveltime for the vertical propagation distance from source to the seafloor, i.e.,

$$
T_{z}=2 t_{z}
$$


Hence, the NMO correction for the direct wave after redatumed to the sea surface is

$$
\Delta T_{\mathrm{NMO}, \text { direct }} \equiv T_{\text {direct }}-T_{z}=t_{\text {direct }}-t_{z}=\Delta t_{\mathrm{NMO}, \text { direct }} .
$$

Using equations 4 and 6 , we can explicitly derive the NMO correction for redatumed traveltime of direct wave in equation 7 as follows:

$$
\Delta T_{\mathrm{NMO}, \text { direct }}=T_{\text {direct }}-T_{z}=\sqrt{\frac{T_{z}^{2}}{4}+\frac{h^{2}}{v^{2}}}-\frac{T_{z}}{2} .
$$

\section{NMO correction for reflected wave}

After redatuming source and receivers to the sea surface, we can apply a conventional NMO correction to the reflected wave. As shown in Figure 8, the NMO correction for the two-way traveltime of reflected wave can be written as follows:

$$
\Delta T_{\mathrm{NMO}, \text { reflected }}=T_{\text {reflected }}-T_{z}=\sqrt{T_{z}^{2}+\frac{h^{2}}{v_{\mathrm{rms}}^{2}}}-T_{z},
$$

where $T_{\text {reflected }}$ is the two-way traveltime of the reflected wave to the virtual receiver after at the sea surface, $T_{z}$ is the two-way traveltime for the vertical propagation distance from source to the reflector, and $v_{\text {rms }}$ is the root-mean-square (RMS) velocity from the sea surface to the reflector. Velocity analysis is required to estimate proper velocities for different reflectors.

\section{Effect of NMO correction on shot profiles}

As shown in equations 8 and 9, the NMO time corrections for direct wave and reflected wave are different in the data where the source and receivers are redatumed to the sea surface. We can also derive the traveltime functions of the direct wave and reflected wave 
presented in the redatumed data. The traveltime of the direct wave is

$$
T_{\text {direct }}=\sqrt{\frac{T_{z}^{2}}{4}+\frac{h^{2}}{v^{2}}}+\frac{T_{z}}{2}
$$

and the traveltime of the reflected wave is

$$
T_{\text {reflected }}=\sqrt{T_{z}^{2}+\frac{h^{2}}{v_{\mathrm{rms}}^{2}}} .
$$

We can illustrate the direct wave and reflected wave in a shot profile from seafloor DAS receivers using a simple 1D velocity model described in Figure 9. The model comprises one seafloor reflector at $30 \mathrm{~ms}$ with $1490 \mathrm{~m} / \mathrm{s}$ RMS velocity, one subsurface reflector at $40 \mathrm{~ms}$ with $1490 \mathrm{~m} / \mathrm{s}$ RMS velocity, and one subsurface reflector at $40 \mathrm{~ms}$ with $1590 \mathrm{~m} / \mathrm{s}$ RMS velocity.

Since the actual receivers are embedded to the seafloor reflector, three key seismic events are presented in the shot profile shown in Figure 9(a). Firstly, the solid blue curve is the direct wave arriving the DAS receivers on the seafloor. Secondly, the dashed orange curve is the wave reflected from the first subsurface reflector with $1490 \mathrm{~m} / \mathrm{s}$ RMS velocity. Thirdly, the dotted green curve is the wave reflected from the second subsurface reflector with $1590 \mathrm{~m} / \mathrm{s}$ RMS velocity. It shows that the first arrival to near-offset DAS receivers is the direct wave, whereas the first arrival to the receivers at far offsets is the reflections from the horizons below the seafloor.

When NMO correction for direct wave using equation 8 is applied, the direct wave becomes flat in the common shot gather; however, all the subsurface reflections below the seafloor are overcorrected as shown in Figure 9(b). On the other hand, the reflections can become flat if NMO correction for reflected wave in equation 9 is applied using a proper velocity. However, the direct wave would be undercorrected as shown in Figure 9(c). 


\section{NMO stretch}

NMO correction causes an inevitable frequency distortion, namely NMO stretching, especially for shallow events and at large offsets. As a result of stretching, seismic events are shifted to lower frequencies. The wavelet with a dominant period $\tau$ is stretched such that its period after NMO correction becomes $\tau_{\mathrm{NMO}}$, which is greater than $\tau$ by $\Delta \tau_{\mathrm{NMO}}$. That is,

$$
\tau_{\mathrm{NMO}}=\tau+\Delta \tau_{\mathrm{NMO}}
$$

Stretching is quantified by the change in the period of the wavelet divided by the initial dominant period, i.e., $\Delta \tau_{\mathrm{NMO}} / \tau$. Hence, stretching for direct wave NMO correction for $\tau \ll T_{z}$ is quantified by

$$
\frac{\Delta \tau_{\mathrm{NMO}, \text { direct }}}{\tau} \approx \frac{\Delta T_{\mathrm{NMO}, \text { direct }}}{T_{z}+\Delta T_{\mathrm{NMO}, \text { direct }}}
$$

where $T_{z}$ is two-way traveltime for the vertical propagation distance from source to the seafloor, and $\Delta T_{\mathrm{NMO} \text {,direct }}$ is given by equation 8 . This equation implies that the NMO stretch can be increased by the decrease of the water depth and the increase of offset. The derivation of equation 13 is given in Appendix C.

On the other hand, stretching for reflected wave NMO correction for $\tau \ll T_{z}$ is quantified by

$$
\frac{\Delta \tau_{\mathrm{NMO}, \text { reflected }}}{\tau} \approx \frac{\Delta T_{\mathrm{NMO}, \text { reflected }}}{T_{z}}
$$

where $T_{z}$ is two-way traveltime for the vertical propagation distance from source to the reflector, $\Delta T_{\mathrm{NMO}}$,reflected is given by equation 9 . This expression is the same as NMO stretching for two-way traveltime reflections for any surface source and surface receiver (Yilmaz, 2001). 


\section{RESULTS AND DISCUSSION}

The key seismic imaging from DAS data begins with the NMO correction. Figure 10 illustrates the results of NMO corrections for direct wave and reflected waves in a super shot gather of the real data. The figure illustrates a supergather at shot number 2161, which is approximately at $2877 \mathrm{~m}$ distance on the cable, which is aligned with the horizontal axis in Figure 11. Coherent seismic events are hardly observed in the prestack seismic gathers without supergathering. This supergathering technique is also applied to enhance the key seismic events for velocity analysis. The NMO corrections for direct wave and reflected waves are independently carried out after noise attenuation, redatuming to sea surface, and data regularization. The velocity models used in the NMO corrections are obtained by time-velocity scanning semblance analysis, where the velocity in water is $1490 \mathrm{~m} / \mathrm{s}$. Note that the data at offsets less than $30 \mathrm{~m}$ are missing in this shot gather. Hence, the first arrivals in all the existing traces are reflected waves, not the direct wave. This observation is aligned with the schematic plot in Figure 9, where the reflected waves may arrive to far-offset receivers earlier than the direct wave.

After NMO corrections are applied, we mute the data with severe NMO stretch at far offset and stack all the traces below the mute function. Then, two stacked section are derived, i.e., one from direct wave and the other from reflected waves. After stacking the NMO corrected gathers of DAS data, we combine the two stacked sections by summing the traces from the same channel. Then, we broaden the amplitude spectrum to be comparable with the reference seismic data from the streamer. We finally apply zero-offset time migration to the stacked data and compare the result with the image from streamer

data in Figure 11. Figure 11(a) and Figure 11(b) show the migrated image from streamer 
and DAS, respectively. The DAS image contains stronger high-frequency noise than the streamer image. The dominant frequency of DAS image is also somewhat lower, and the bandwidth is narrower than the streamer image.

We observe that the DAS image below the seafloor is contaminated by high-frequency noise, while the streamer image is somewhat cleaner. Therefore, we apply additional signal enhancement processing to the image by trace mixing of surrounding 21 traces and applying a high-cut filter at $480 \mathrm{~Hz}$. These additional steps are applied to both streamer and DAS images, and the results are shown in Figure 11(c) and Figure 11(d), respectively. After signal enhancement, the continuity of the seafloor images is improved, and the subsurface reflections in the images become obvious and easy to interpret. Key seismic reflections can be observed in both images as highlighted as the yellow arrows in the figure However, the signal enhancement reduces the frequency bandwidth and, hence, the image resolution. Therefore, the trade-off between enhancing the signal and maintaining the frequency bandwidth should be carefully tested to optimize the DAS image quality.

The geological image from streamer data results from seismic reflections, while the direct wave does not penetrate through any structure below the seafloor. Hence, the direct wave in streamer data is considered as noise. On the other hand, the DAS seismic imaging uses both direct wave and reflections to construct the geological image. Figure 11(d) illustrates that the seafloor and underlying subsurface structures can be imaged from DAS seismic data by our processing sequence. The seafloor and subsurface image from DAS data is comparable with the reference image from streamer data in Figure 11(c). Note that the DAS image represents the image at a different position from the streamer data, since their receiver positions are different. Therefore, the subsurface structures in the images from streamer and DAS are slightly different. 
We observe that the DAS image has low resolution in the shallowest part of the line between $2500 \mathrm{~m}$ and $2700 \mathrm{~m}$, where the crossline offset is larger than the water depth. The primary reason is that our DAS data lack near-offset information, while the water depth is shallow at these locations. Therefore, the effect of NMO stretch becomes significant and causes a low dominant frequency content in the NMO result, especially for the water bottom event. Note that NMO stretch for the water bottom event depends on water depth and offset according to equation 13. The stretch increases with the decrease of the water depth and the increase of offset. Figure 12(a) and Figure 12(b) illustrate the variations of water depth and minimum offset at different receiver positions. The minimum offset is the crossline offset $\left(h_{y}\right)$ as illustrated in Figure 6. In addition, Figure 12(c) shows the minimum stretch associated with the water bottom event. We observe that the minimum NMO stretch for DAS data is significantly larger than the minimum stretch for towed streamer data. Thus, the water bottom image from DAS has lower resolution than the image from towed streamer as shown in Figure 11. The resolution of DAS image is extremely low in the shallow water area at 2500-2600 $\mathrm{m}$ along the cable. To obtain a higher resolution image, we should have controlled the seismic source to be laterally closer to the DAS cable. That is, we must reduce the crossline offset between source and the DAS cable during the survey, so that the NMO stretch is minimized. Then, a higher resolution seismic image can be achieved. The requirement of short crossline offset is crucial especially for any shallow water environment.

The effect of NMO stretch is illustrated in Figure 13, where a near trace gather of the DAS data is shown. The gather represents the DAS data with nearly zero inline offset. That is, the offset of each trace in the gather is approximately equal to the crossline offset. In Figure 13(a), we observe coherent seismic events (direct wave) that would contribute to the seafloor image. These events have comparable temporal resolution to the streamer data as 
shown in Figure 4. The key coherent seismic events are indicated by the black arrows in the figure. When NMO correction for the direct wave is applied, the events are shifted in time and their characteristics are deformed by NMO stretch. NMO stretch deforms the wavelet to have lower frequency than the original form. As shown in Figure 13(b), the stretch is enormous especially in the shallow water depth and large crossline offset like event "A". In contrast, we see less NMO stretch where the crossline offset is short, and the water is deep like event "B". This observation is aligned with the plot of minimum stretch in Figure 12(c).

The quality of an image can be evaluated by $\mathrm{S} / \mathrm{N}$. Hence, we use $\mathrm{S} / \mathrm{N}$ to quantitatively compare the quality of the DAS and streamer images. In our analysis, $\mathrm{S} / \mathrm{N}$ of the $i^{\text {th }}$ trace is defined as the ratio of the power of the signal $\left(P_{\text {signal }, i}\right)$ within the trace to the average background noise $\left(P_{\text {noise }}\right)$ of the whole survey:

$$
(\mathrm{S} / \mathrm{N})_{i}=\frac{P_{\text {signal }, i}}{P_{\text {noise }}}=\left(\frac{A_{\text {signal }, i}}{A_{\text {noise }}}\right)^{2}
$$

where $A_{\text {signal }, i}$ is RMS amplitude of the samples within the signal window from the $i^{\text {th }}$ trace, and $A_{\text {noise }}$ is RMS amplitude of the samples within the background noise window from all the traces. As plotted in Figure 11, the signal window is defined between orange and green horizons, whereas noise window is defined between blue and orange horizons. The ratio can be expressed in decibels $(\mathrm{dB})$ as

$$
(\mathrm{S} / \mathrm{N})_{\mathrm{dB}}=10 \log _{10}(\mathrm{~S} / \mathrm{N})
$$

Figure 14(a) compares $\mathrm{S} / \mathrm{N}$ in $\mathrm{dB}$ of the images from DAS and towed streamer around the water bottom. We observe that the image from towed streamer generally have higher $\mathrm{S} / \mathrm{N}$ than the DAS image, especially when the seafloor is shallow. On the other hand, Figure 14(b) compares the normalized power spectrum of the images in the signal window from streamer and DAS after the same postmigration signal enhancement processing. We 
observe that DAS image has lower dominant frequency than streamer image. Moreover, DAS image contains more low frequency contents than the streamer image.

We should also note that our comparison is not one-to-one in the sense that the streamer data result from the summation of the 24 hydrophone elements (approximately $7 \mathrm{~m}$ ) into one single channel. Stacking of 24 hydrophone elements corresponds to an improved S/N of the square root of the number of stacking elements (nearly 5 times in this case). This is the major explanation why the raw streamer data have less noise compared to the raw DAS data. The DAS data are recorded from each sensing element with a gauge length of $4 \mathrm{~m}$. Furthermore, under an angle mute function, we sum the recorded data from at least 40 channels of $2 \mathrm{~m}$ spacing (approximately $80 \mathrm{~m}$ ) with obvious signals as observed in Figure 5 to form a single trace of the DAS image in Figure 11(b) and Figure 11(d). The multi-channel summation of the DAS data significantly enhances the S/N. However, the optimal number of channels to be summed is still limited by the desired temporal resolution associated with the offset-dependent NMO stretch. Therefore, we recommend testing the mute function for stacking in order to compromise the signal enhancement with the temporal resolution.

Our seismic analysis covers the range from 160-480 Hz, corresponding to the wavelengths in the range of 9.4 to $3.1 \mathrm{~m}$ with the velocity of $1490 \mathrm{~m} / \mathrm{s}$. However, the bandwidth of the seismic source used in this experiment ranges from $350-1000 \mathrm{~Hz}$ with the dominant frequency at about $600 \mathrm{~Hz}$. For wave velocities in the order of $1490 \mathrm{~m} / \mathrm{s}$ this corresponds to wavelengths in the range of 4.3 to $1.5 \mathrm{~m}$, with the dominant energy at a wavelength of $2.5 \mathrm{~m}$. Thus, with a DAS interrogator operating with a $4 \mathrm{~m}$ gauge length, the seismic waves with the frequency greater than $375 \mathrm{~Hz}$ generated from our current source cannot properly be resolved by DAS. Using a seismic source with stronger low frequency emission or operating the DAS interrogator at shorter gauge lengths should therefore improve the DAS 
image resolution. Furthermore, with a more powerful source at low frequencies, it might be possible to utilize more DAS channels at larger offsets (a longer cable length) to construct a larger aperture which might improve the spatial resolution and provide deeper imaging capabilities with DAS. Note that the seismic source used in our experiment is relatively weak compared to conventional seismic sources such as air guns.

Our major objective of this article is to achieve a qualitative comparison of the two types of data to demonstrate the enormous potential for DAS data, despite higher background noise level. The tremendous advantage for the DAS data is the number of channels in the long fiber optic cable. We aim to indicate that it is possible for DAS to record data over a long distance (several kilometers) to form the subsurface image with comparable quality as the conventional streamer. The advantage of having excessive receivers over a long distance can be exploited for several other applications, such as tracking the positions of marine vessels, marine mammals, earthquakes and so on. However, this article is limited to a simple comparison of conventional seismic imaging to DAS imaging using the same seismic source.

The results shown in this article clearly prove that we can use DAS cables together with controlled seismic sources to construct the subsurface image comparable to a conventional seismic survey using towed streamers. To obtain a DAS image with high quality and high $\mathrm{S} / \mathrm{N}$, we require sufficient source energy within the frequency range limited by the gauge length, which implies the spatial resolution of DAS. Moreover, we have to minimize the crossline offset between the source and the DAS cable during the survey to prevent excessive stretch and improve the image resolution. Thus, we can conclude that it is possible to use DAS from existing dark fiber optic cables together with appropriate seismic sources for subsurface imaging. If a conventional seismic survey is conducted above recording DAS 
cables, the near surface seismic image from DAS can be obtained and used for geohazard analysis prior to any construction on the seafloor. Hence, we envisage many possibilities of DAS to support various subsurface exploration activities.

\section{CONCLUSION}

This article shows that DAS from submarine telecommunication fiber optic cables can be used together with appropriate seismic sources to construct the seafloor and subsurface structural images. We also discuss the strategy to estimate the position of an unknown source from the direct wave recorded by DAS cable, so that seismic imaging from unknown sources is plausible. We use an optical cable on the seafloor in Trondheim Fjord, Norway, to record seismic data from controlled sources. The data are simultaneously recorded by a towed single-channel streamer with a 24-element hydrophone array of $7 \mathrm{~m}$ active length for comparison. In this article, we show that we can derive the DAS image from direct wave and subsurface reflections resulting from controlled seismic sources. The quality of the images can be improved by using a seismic source with sufficiently large energy within the lowfrequency range matching the spatial resolution of DAS. A low frequency seismic source would also improve the penetration to deeper geological structures, and, hence, deeper seismic images. On the other hand, the temporal resolution can be improved by minimizing the crossline offset between seismic sources and the DAS cable to reduce the NMO stretch effect. For water depths larger than the offset range used for DAS imaging, we find that DAS and hydrophone data have about the same S/N. The DAS recording can be carried simultaneously with any conventional seismic survey to support geohazard analysis below the seafloor and various subsurface exploration activities. The operational advantages of DAS over node systems and the validity of DAS for near surface seismic imaging as shown 
in this article will sustain the growth of DAS in the seabed seismic market.

\section{APPENDIX A}

\section{DISTANCE BETWEEN SOURCE AND CABLE}

From Figure 6, we define that $t_{0}$ is the UTC time when the source is fired, $t$ is the UTC time when the direct wave arrives to a receiver, and $\tau$ is its traveltime from source to the receiver. Thus,

$$
\tau=t-t_{0}
$$

Assuming the constant velocity $v$, we can compute the travel distance of the direct wave from source to the receiver with the inline offset $h_{x}$ as follows:

$$
v \tau=\sqrt{d^{2}+h_{x}^{2}}
$$

where $d$ is the distance between source and the DAS cable. Hence, the traveltime of the direct wave can be written as a function of the inline offset $h_{x}$ as follows:

$$
\tau_{\left\{h_{x}\right\}}=\frac{1}{v} \sqrt{d^{2}+h_{x}^{2}}
$$

The subscription to the variable $\tau$ denotes the variation of the traveltime with the inline offset $h_{x}$. To the receiver at zero inline offset $\left(h_{x}=0\right)$, the traveltime becomes minimal at

$$
\tau_{\left\{h_{x}=0\right\}}=\frac{d}{v}
$$

Hence, the difference between the traveltime at zero inline offset and the traveltime at an arbitrary offset is defined as follows:

$$
\Delta \tau=\tau_{\left\{h_{x}\right\}}-\tau_{\left\{h_{x}=0\right\}}=\frac{1}{v} \sqrt{d^{2}+h_{x}^{2}}-\frac{d}{v} .
$$


Rearranging equation A-5, we obtain equation 1 by the following approaches:

$$
\begin{aligned}
\Delta \tau+\frac{d}{v} & =\frac{1}{v} \sqrt{d^{2}+h_{x}^{2}} \\
\left(\Delta \tau+\frac{d}{v}\right)^{2} & =\frac{1}{v^{2}}\left(d^{2}+h_{x}^{2}\right) \\
(\Delta \tau)^{2}+2(\Delta \tau)\left(\frac{d}{v}\right)+\frac{d^{2}}{v^{2}} & =\frac{d^{2}}{v^{2}}+\frac{h_{x}^{2}}{v^{2}} \\
d & =\frac{v}{2 \Delta \tau}\left(\frac{h_{x}^{2}}{v^{2}}-(\Delta \tau)^{2}\right) .
\end{aligned}
$$

\section{APPENDIX B}

\section{DAS DATA PROCESSING SEQUENCE}

The processing sequence for DAS data is summarized as follows:

1. Do radial trace mixing by summing the seismic traces from neighboring shots $(3: 1$ shots).

2. Apply a band-pass frequency filter for $160 \mathrm{~Hz} / 20 \mathrm{~dB}-960 \mathrm{~Hz} / 20 \mathrm{~dB}$.

3. Apply static correction to redatum both source and receivers to the sea surface.

4. Regularize seismic data using offset bin spacing of $1 \mathrm{~m}$.

5. Apply NMO correction to correct the traveltime from arbitrary offsets to zero offset for the two events below separately using different correction methods:

(a) The direct arrival from source to the DAS receivers on the seafloor.

(b) The primary reflections from the geological structures underlying the seafloor.

6. Attenuate the multiple reflections in Radon domain. 
7. Mute out the undesired stretches at far offsets (0-30 degrees with $76 \mathrm{~m}$ preserved minimum offset)

8. Stack the NMO data from all offset bins.

9. Combine the NMO stacks from both direct arrival and reflections to construct a zero-offset seismic reflection data where source and receivers are virtually at the sea surface.

10. Apply spectral whitening.

11. Apply zero-offset time migration using the NMO velocity for primary reflections.

12. Do radial trace mixing by summing the seismic traces from surrounding 21 traces.

13. Apply a high-cut filter at $480 \mathrm{~Hz} / 20 \mathrm{~dB}$.

\section{APPENDIX C}

\section{MOVEOUT STRETCH FOR DIRECT WAVE}

Considering the DAS data after redatuming the source and receivers to the sea surface, the direct wave moveout equation associated with the onset of the wavelet with the arrival time $T_{\text {direct }}$ at offset $h$ is given by equation 10 . This expression can be rearranged as follows:

$$
\begin{aligned}
\left(T_{\text {direct }}-\frac{T_{z}}{2}\right)^{2} & =\frac{T_{z}^{2}}{4}+\frac{h^{2}}{v^{2}} \\
T_{\text {direct }}^{2}-T_{\text {direct }} T_{z}+\frac{T_{z}^{2}}{4} & =\frac{T_{z}^{2}}{4}+\frac{h^{2}}{v^{2}} \\
T_{\text {direct }}^{2}-T_{\text {direct }} T_{z} & =\frac{h^{2}}{v^{2}} .
\end{aligned}
$$

After applying NMO correction for the direct wave, the wavelet of dominant period $\tau$ is stretched, then its dominant period becomes $\tau_{\mathrm{NMO}}=\tau+\Delta \tau_{\mathrm{NMO}}$, direct as previously defined 
in equation 12. Thus, the moveout equation associated with the termination of this wavelet can be derived by replacing $T_{\text {direct }}$ with $T_{\text {direct }}+\tau$, and replacing $T_{z}$ with $T_{z}+\tau_{\mathrm{NMO}}$ in equation C-3. That is,

$$
\begin{gathered}
\left(T_{\text {direct }}+\tau\right)^{2}-\left(T_{\text {direct }}+\tau\right)\left(T_{z}+\tau+\Delta \tau_{\mathrm{NMO}, \text { direct }}\right)=\frac{h^{2}}{v^{2}} \\
\left(T_{\text {direct }}^{2}+2 T_{\text {direct }} \tau+\tau^{2}\right) \\
-T_{\text {direct }} T_{z}-T_{\text {direct }} \tau-T_{\text {direct }} \Delta \tau_{\mathrm{NMO} \text {,direct }} \\
-\tau T_{z}-\tau^{2}-\tau \Delta \tau_{\mathrm{NMO}, \text { direct }}=\frac{h^{2}}{v^{2}} \\
{\left[\left(T_{\text {direct }}^{2}-T_{\text {direct }} T_{z}\right)-\frac{h^{2}}{v^{2}}\right]} \\
+\left(T_{\text {direct }}-T_{z}\right) \tau=\left(T_{\text {direct }}+\tau\right) \Delta \tau_{\mathrm{NMO}, \text { direct }} .
\end{gathered}
$$

The first term on the left-hand side of the last equation becomes zero by the relation in equation C-3. Accordingly, using the definition of $\Delta T_{\mathrm{NMO} \text {,direct }}$ from equation 7 , we can derive the moveout stretch for direct wave from equation C-6 as follows:

$$
\begin{aligned}
\left(\Delta T_{\mathrm{NMO}, \text { direct }}\right) \tau & =\left(T_{z}+\Delta T_{\mathrm{NMO}, \text { direct }}+\tau\right) \Delta \tau_{\mathrm{NMO}, \text { direct }} \\
\frac{\Delta \tau_{\mathrm{NMO}, \text { direct }}}{\tau} & =\frac{\Delta T_{\mathrm{NMO}, \text { direct }}}{T_{z}+\Delta T_{\mathrm{NMO}, \text { direct }}+\tau} .
\end{aligned}
$$

Assuming that $\tau \ll T_{z}$, the moveout stretch for direct wave can be approximated by the following expression:

$$
\frac{\Delta \tau_{\mathrm{NMO}, \text { direct }}}{\tau} \approx \frac{\Delta T_{\mathrm{NMO}, \text { direct }}}{T_{z}+\Delta T_{\mathrm{NMO}, \text { direct }}}
$$




\section{REFERENCES}

Ajo-Franklin, J., S. Dou, T. Daley, B. Freifeld, M. Robertson, C. Ulrich, T. Wood, I. Eckblaw, N. Lindsey, E. Martin, and A. Wagner, 2017, Time-lapse surface wave monitoring of permafrost thaw using distributed acoustic sensing and a permanent automated seismic source: SEG Technical Program Expanded Abstracts 2017, Society of Exploration Geophysicists, 5223-5227.

Ajo-Franklin, J., N. Lindsey, T. Daley, B. Freifeld, M. Robertson, C. Ulrich, S. Dou, E. Martin, and A. Wagner, 2015, A Field Test of Distributed Acoustic Sensing for Ambient Noise Recording: SEG Technical Program Expanded Abstracts 2015, Society of Exploration Geophysicists, 2620-2624.

Ajo-Franklin, J. B., S. Dou, N. J. Lindsey, I. Monga, C. Tracy, M. Robertson, V. Rodriguez Tribaldos, C. Ulrich, B. Freifeld, T. Daley, and X. Li, 2019, Distributed Acoustic Sensing Using Dark Fiber for Near-Surface Characterization and Broadband Seismic Event Detection: Scientific Reports, 9, 1328.

Biondi, B., E. Martin, S. Cole, M. Karrenbach, and N. Lindsey, 2017, Earthquakes analysis using data recorded by the Stanford DAS array: SEG Technical Program Expanded Abstracts 2017, Society of Exploration Geophysicists, 2752-2756.

Daley, T. M., B. M. Freifeld, J. Ajo-Franklin, S. Dou, R. Pevzner, V. Shulakova, S. Kashikar, D. E. Miller, J. Goetz, J. Henninges, and S. Lueth, 2013, Field testing of fiber-optic distributed acoustic sensing (DAS) for subsurface seismic monitoring: The Leading Edge, 32, 699-706.

Dean, T., T. Brice, A. Hartog, E. Kragh, D. Molteni, and K. O'Connell, 2016, Distributed vibration sensing for seismic acquisition: The Leading Edge, 35, 600-604. (Publisher: Society of Exploration Geophysicists). 
Dou, S., N. Lindsey, A. M. Wagner, T. M. Daley, B. Freifeld, M. Robertson, J. Peterson, C. Ulrich, E. R. Martin, and J. B. Ajo-Franklin, 2017, Distributed Acoustic Sensing for Seismic Monitoring of The Near Surface: A Traffic-Noise Interferometry Case Study: Scientific Reports, 7, 11620.

Fang, G., Y. E. Li, Y. Zhao, and E. R. Martin, 2020, Urban Near-Surface Seismic Monitoring Using Distributed Acoustic Sensing: Geophysical Research Letters, 47.

Fernández-Ruiz, M. R., M. A. Soto, E. F. Williams, S. Martin-Lopez, Z. Zhan, M. GonzalezHerraez, and H. F. Martins, 2020, Distributed acoustic sensing for seismic activity monitoring: APL Photonics, 5, 030901.

Hartog, A. H., 2017, An Introduction to Distributed Optical Fibre Sensors, 1 ed.: CRC Press.

Kowarik, S., M.-T. Hussels, S. Chruscicki, S. Münzenberger, A. Lämmerhirt, P. Pohl, and M. Schubert, 2020, Fiber Optic Train Monitoring with Distributed Acoustic Sensing: Conventional and Neural Network Data Analysis: Sensors, 20, 450.

Landrø, M., and L. Amundsen, 2018, Introduction to exploration geophysics with recent advances: Bivrost Geo. (OCLC: 1060774435).

Langhammer, J., M. Eriksrud, and H. Nakstad, 2010, Performance characteristics of 4C fiber optic ocean bottom cables for permanent reservoir monitoring: SEG Technical Program Expanded Abstracts 2010, Society of Exploration Geophysicists, 66-70.

Lindsey, N. J., T. C. Dawe, and J. B. Ajo-Franklin, 2019, Illuminating seafloor faults and ocean dynamics with dark fiber distributed acoustic sensing: Science, 366, 1103-1107.

Lindsey, N. J., S. Yuan, A. Lellouch, L. Gualtieri, T. Lecocq, and B. Biondi, 2020, City-Scale Dark Fiber DAS Measurements of Infrastructure Use During the COVID-19 Pandemic: Geophysical Research Letters, 47. 
Lumens, P., 2014, Fibre-optic sensing for application in oil and gas wells: PhD thesis, Technische Universiteit Eindhoven.

Martin, E. R., C. M. Castillo, S. Cole, P. S. Sawasdee, S. Yuan, R. Clapp, M. Karrenbach, and B. L. Biondi, 2017, Seismic monitoring leveraging existing telecom infrastructure at the SDASA: Active, passive, and ambient-noise analysis: The Leading Edge, 36, 10251031.

Martin, E. R., F. Huot, Y. Ma, R. Cieplicki, S. Cole, M. Karrenbach, and B. L. Biondi, 2018, A Seismic Shift in Scalable Acquisition Demands New Processing: Fiber-Optic Seismic Signal Retrieval in Urban Areas with Unsupervised Learning for Coherent Noise Removal: IEEE Signal Processing Magazine, 35, 31-40.

Monrigal, O., I. de Jong, and H. Duarte, 2017, An ultra-high-resolution 3D marine seismic system for detailed site investigation: Near Surface Geophysics, 15, 335-345.

Papp, B., D. Donno, J. E. Martin, and A. H. Hartog, 2017, A study of the geophysical response of distributed fibre optic acoustic sensors through laboratory-scale experiments: Geophysical response of fibre optic sensors: Geophysical Prospecting, 65, 1186-1204.

Sladen, A., D. Rivet, J. P. Ampuero, L. De Barros, Y. Hello, G. Calbris, and P. Lamare, 2019, Distributed sensing of earthquakes and ocean-solid Earth interactions on seafloor telecom cables: Nature Communications, 10, 5777.

Thomas, Y., B. Marsset, G. Westbrook, C. Grail, L. Géli, P. Henry, G. Çifçi, A. Rochat, and H. Saritas, 2012, Contribution of high-resolution 3D seismic near-seafloor imaging to reservoir-scale studies: application to the active North Anatolian Fault, Sea of Marmara: Near Surface Geophysics, 10, 291-301.

Vinje, V., J. E. Lie, V. Danielsen, P. E. Dhelie, R. Siliqi, C.-I. Nilsen, E. Hicks, and A. Camerer, 2017, Shooting over the seismic spread: First Break, 35, 8. 
Walter, F., D. Gräff, F. Lindner, P. Paitz, M. Köpfli, M. Chmiel, and A. Fichtner, 2020, Distributed acoustic sensing of microseismic sources and wave propagation in glaciated terrain: Nature Communications, 11, 2436.

Wang, Y., H. Yuan, X. Liu, Q. Bai, H. Zhang, Y. Gao, and B. Jin, 2019, A Comprehensive Study of Optical Fiber Acoustic Sensing: IEEE Access, 7, 85821-85837.

Williams, E. F., M. R. Fernández-Ruiz, R. Magalhaes, R. Vanthillo, Z. Zhan, M. GonzálezHerráez, and H. F. Martins, 2019, Distributed sensing of microseisms and teleseisms with submarine dark fibers: Nature Communications, 10, 5778.

Yilmaz, z., 2001, Seismic Data Analysis: Society of Exploration Geophysicists. Investigations in Geophysics.

Yu, C., Z. Zhan, N. J. Lindsey, J. B. Ajo-Franklin, and M. Robertson, 2019, The Potential of DAS in Teleseismic Studies: Insights From the Goldstone Experiment: Geophysical Research Letters, 46, 1320-1328.

Zhu, T., J. Shen, and E. R. Martin, 2020, Sensing earth and environment dynamics by telecommunication fiber-optic sensors: An urban experiment in pennsylvania usa: Solid Earth Discussions, 2020, 1-30. 


\section{LIST OF FIGURES}

1 Photos of (a) NTNU's research vessel Gunnerus (retrieved from https://www . flickr.com/photos/trondheimhavn/5036332012/), and (b) the crew in action to recover the HMS-620 Bubble Gun source.

2 Preplot source and receiver location map of the marine seismic survey in the Trondheim Fjord, Norway. The vessel route (dashed red line) is controlled to be close to the DAS receiver cable (solid pink line) as much as possible. The receiver positions are annotated as the distance from shore along the DAS cable. The background water depth map is shown by courtesy of Kartverket (Norwegian Mapping Authority). The figure was made with QGIS.

3 Top view of the acquisition layout. The source and the streamer are towed approximately $20 \mathrm{~m}$ behind R/V Gunnerus.

4 A common-channel seismic gather recorded by a towed single-channel streamer of $7 \mathrm{~m}$ hydrophone array (24 elements). The average shotpoint interval is $0.275 \mathrm{~m}$. The direct wave (A) and the reflections from the seafloor (B) and subsurface structures (C) are presented.

5 A shot profile (shot number 951) of multi-channel DAS seismic records: (a) raw data, and (b) data after applying a band-pass filter of $160-600 \mathrm{~Hz}$ for illustration. The direct wave from source to the receivers on the seafloor is the hyperbola in the shot profile as indicated by the yellow arrow. However, the underlying subsurface reflections are hardly observed.

6 DAS recording system and its seismic source, where $\tau$ is the traveltime that the wave directly propagates from source to a receiver at the inline offset $h_{x}$. At the receiver with zero inline offset $\left(h_{x}=0\right)$, the traveltime is shortest and equal to $\tau_{\left\{h_{x}=0\right\}}=\frac{d}{v}$, where $d$ is the distance between the source and DAS cable. 
7 Description of NMO correction for the one-way traveltime of the direct wave in DAS recording system: (a) the geometry of the direct wave, and (b) the schematic plot of the direct wave in a shot gather before and after NMO correction. The traveltime of the direct wave is equal to the one-way traveltime along the vertical propagation distance to the seafloor.

8 Description of NMO correction for two-way traveltime of the seismic reflection in DAS recording system.

9 Illustration of different NMO correction methods for DAS recording on the 1D model comprising one seafloor reflector at $30 \mathrm{~ms}$ with $1490 \mathrm{~m} / \mathrm{s}$ RMS velocity, one subsurface reflector at $40 \mathrm{~ms}$ with $1490 \mathrm{~m} / \mathrm{s}$ RMS velocity, and one subsurface reflector at $40 \mathrm{~ms}$ with $1590 \mathrm{~m} / \mathrm{s}$ RMS velocity. The traveltime is referenced to the datum at sea surface. (a) Schematic shot profile of synthetic seafloor DAS data after redatuming the source and receivers to the sea surface. (b) The result of NMO correction for the direct wave using $1490 \mathrm{~m} / \mathrm{s}$ velocity. (c) The result of NMO correction for the subsurface reflection using $1590 \mathrm{~m} / \mathrm{s}$ velocity. Since the actual receivers are embedded to the seafloor reflector, three key seismic events are presented in the shot profile: (1) The solid blue curve is the direct wave arriving the DAS receivers on the seafloor; (2) The dashed orange curve is the wave reflected from the first subsurface reflector with $1490 \mathrm{~m} / \mathrm{s}$ RMS velocity; (3) The dotted green curve is the wave reflected from the second reflector with $1590 \mathrm{~m} / \mathrm{s}$ RMS velocity.

10 NMO corrections for the real DAS data set after redatuming to the sea surface and regularization. Supergathering the data from 21 shots around the shot number 2161, of which the position is approximately at $2877 \mathrm{~m}$ on the cable, is made to enhance $\mathrm{S} / \mathrm{N}$ for illustration: (a) A super shot gather sorted by regularized absolute horizontal offsets from source to the DAS receivers. (b) The result of NMO correction for direct wave. (c) The 
result of NMO correction for reflected wave. The dashed blue line is the direct wave event and the dashed orange line is a key reflection event, which are estimated by the associated time-velocity picks. The solid yellow line is the external mute function to be applied before stacking the data along offset.

11 Poststack time migrated seismic images from different data sets: (a) the reference image from a towed single-channel streamer with a 24-element hydrophone array of $7 \mathrm{~m}$ active length, (b) the image from seabed DAS with $4 \mathrm{~m}$ gauge length, (c) the image of (a) with additional signal enhancement applied, and (d) the image of (b) with the same enhancement applied. The seismic events associated with the water bottom and subsurface reflections are presented in both images. Subsurface reflections in DAS image are highlighted by yellow arrows in comparison with the reference image. The horizontal axis is the distance along the cable. The horizons plotted in (c) and (d) define the signal and noise windows for computing the $\mathrm{S} / \mathrm{N}$ and spectrum in Figure 14. Signal window is defined between orange and green horizons, whereas noise window is defined between blue and orange horizons.

12 Plots of the following variables at different positions along DAS cable: a) the water depth; b) the crossline horizontal offset from source to the DAS cable, which is the minimum offset for each source position; and c) the minimum NMO stretch associated with the water bottom events in seismic data recorded by DAS (solid blue line) and towed streamer (dashed orange line). The minimum offset for towed streamer is assumed to be $10 \mathrm{~m}$ throughout the survey.

13 Illustration of NMO stretch effect on a near trace gather of DAS data where sources and receivers are redatumed to the sea surface: (a) near trace gather from the DAS data with common inline offset, and (b) the same gather after NMO correction for the direct 
wave is applied. Each trace of the near trace gather is formed by stacking the seismic traces with the inline offset less than $2 \mathrm{~m}$ from the corresponding shot gather. The absolute offset of each trace in the near trace gather is approximately equal to the crossline offset. The black arrows indicate the key events before and after NMO correction: event "A" has a large stretch effect after NMO, while event "B" only has a small effect from NMO stretch. The NMO stretch depends on the water depth and crossline offset as illustrated in Figure 12.

14 QC plots corresponding to the seismic images from DAS (blue) and towed streamer (orange) with additional signal enhancement applied as shown in Figure 11(c) and Figure 11(d): (a) S/N at different seismic traces, and (b) normalized amplitude spectrum within the signal window. Signal window is defined between orange and green horizons, whereas noise window is defined between blue and orange horizons in Figure 11. 
a)

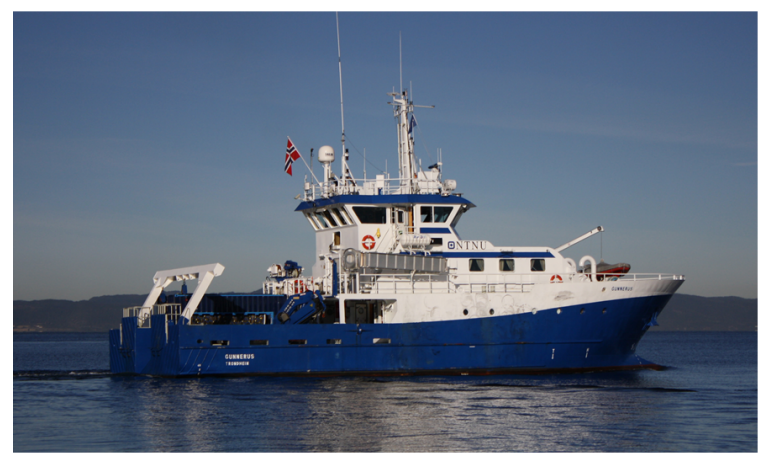

b)

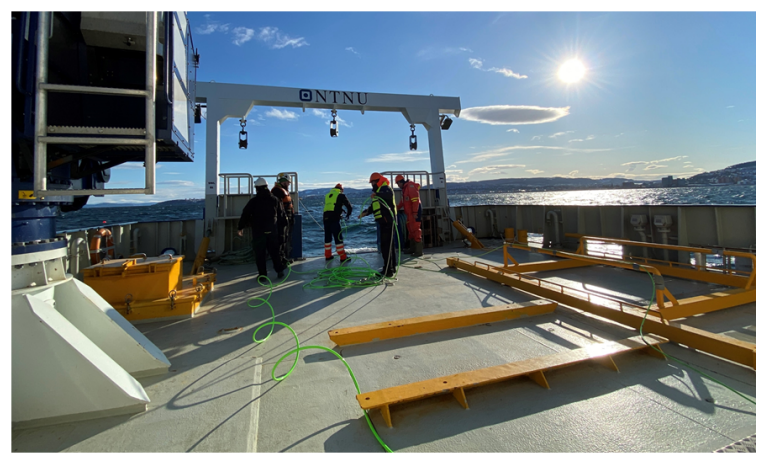

Figure 1: Photos of (a) NTNU's research vessel Gunnerus (retrieved from https://www. flickr.com/photos/trondheimhavn/5036332012/), and (b) the crew in action to recover the HMS-620 Bubble Gun source.

- This non-peer reviewed preprint submitted to EarthArXiv was submitted to Geophysics journal for peer review. 


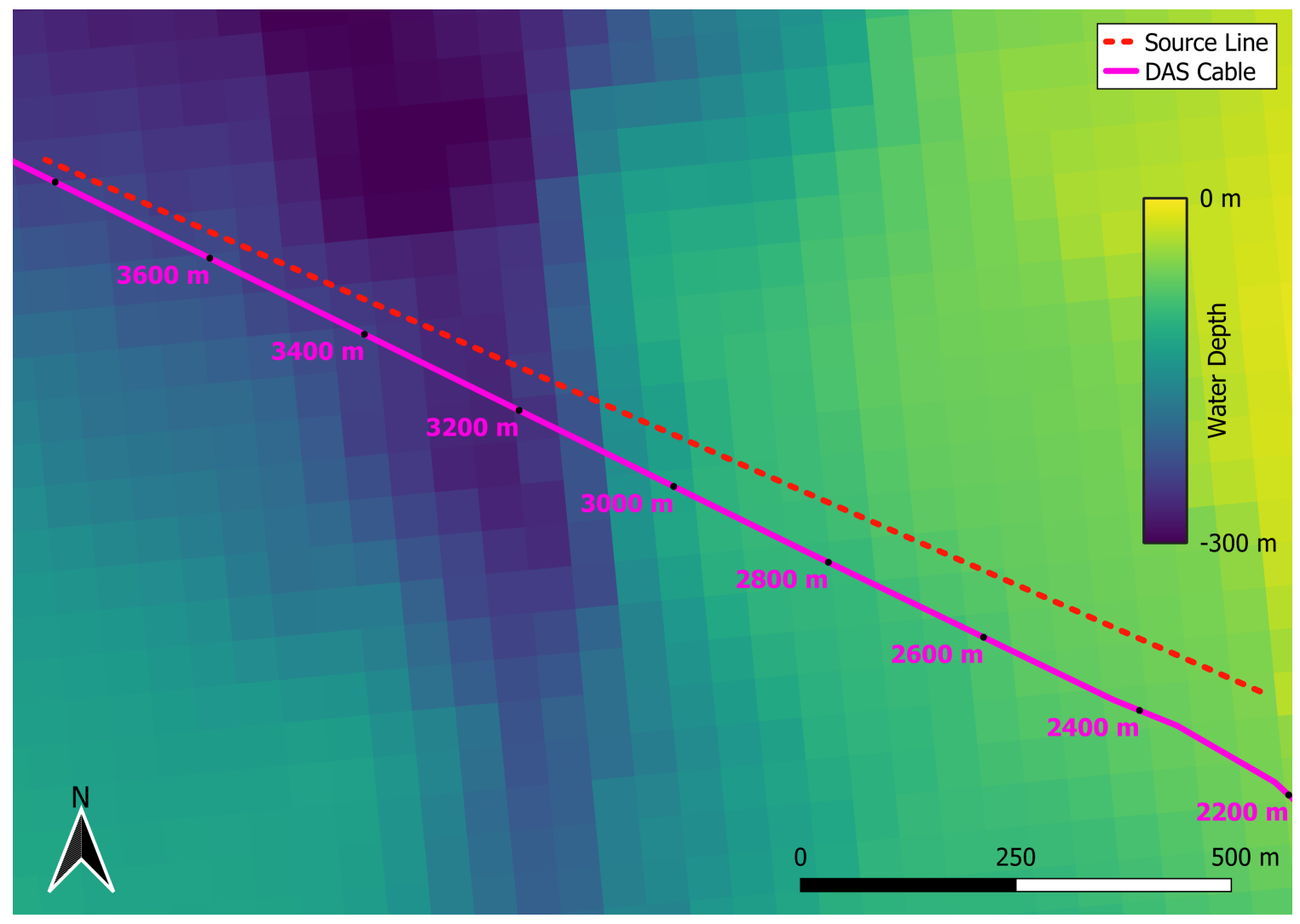

Figure 2: Preplot source and receiver location map of the marine seismic survey in the Trondheim Fjord, Norway. The vessel route (dashed red line) is controlled to be close to the DAS receiver cable (solid pink line) as much as possible. The receiver positions are annotated as the distance from shore along the DAS cable. The background water depth map is shown by courtesy of Kartverket (Norwegian Mapping Authority). The figure was made with QGIS.

- This non-peer reviewed preprint submitted to EarthArXiv was submitted to Geophysics journal for peer review. 


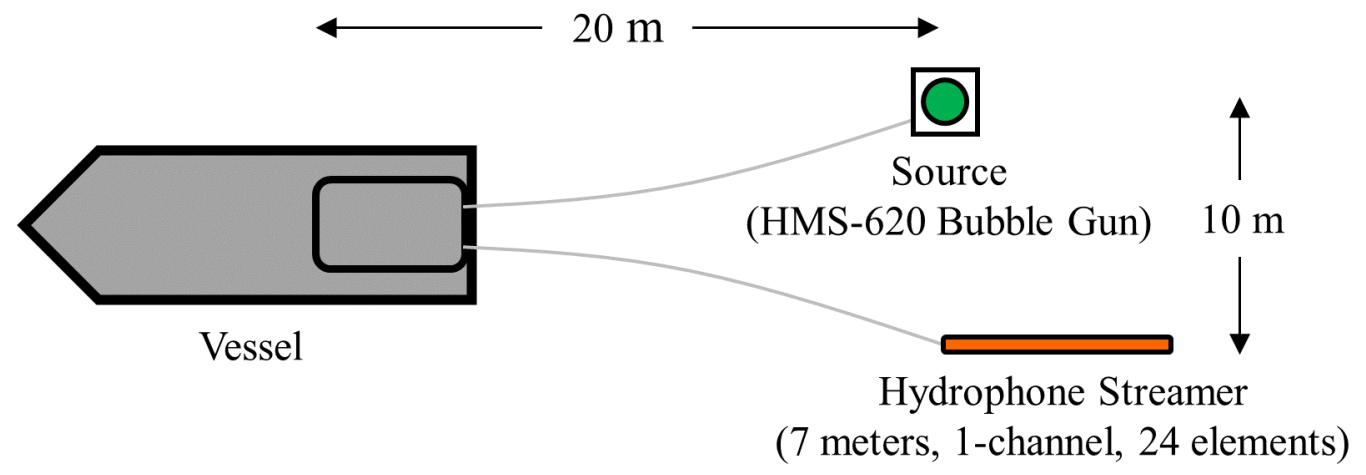

Figure 3: Top view of the acquisition layout. The source and the streamer are towed approximately $20 \mathrm{~m}$ behind R/V Gunnerus.

- This non-peer reviewed preprint submitted to EarthArXiv was submitted to Geophysics journal for peer review. 


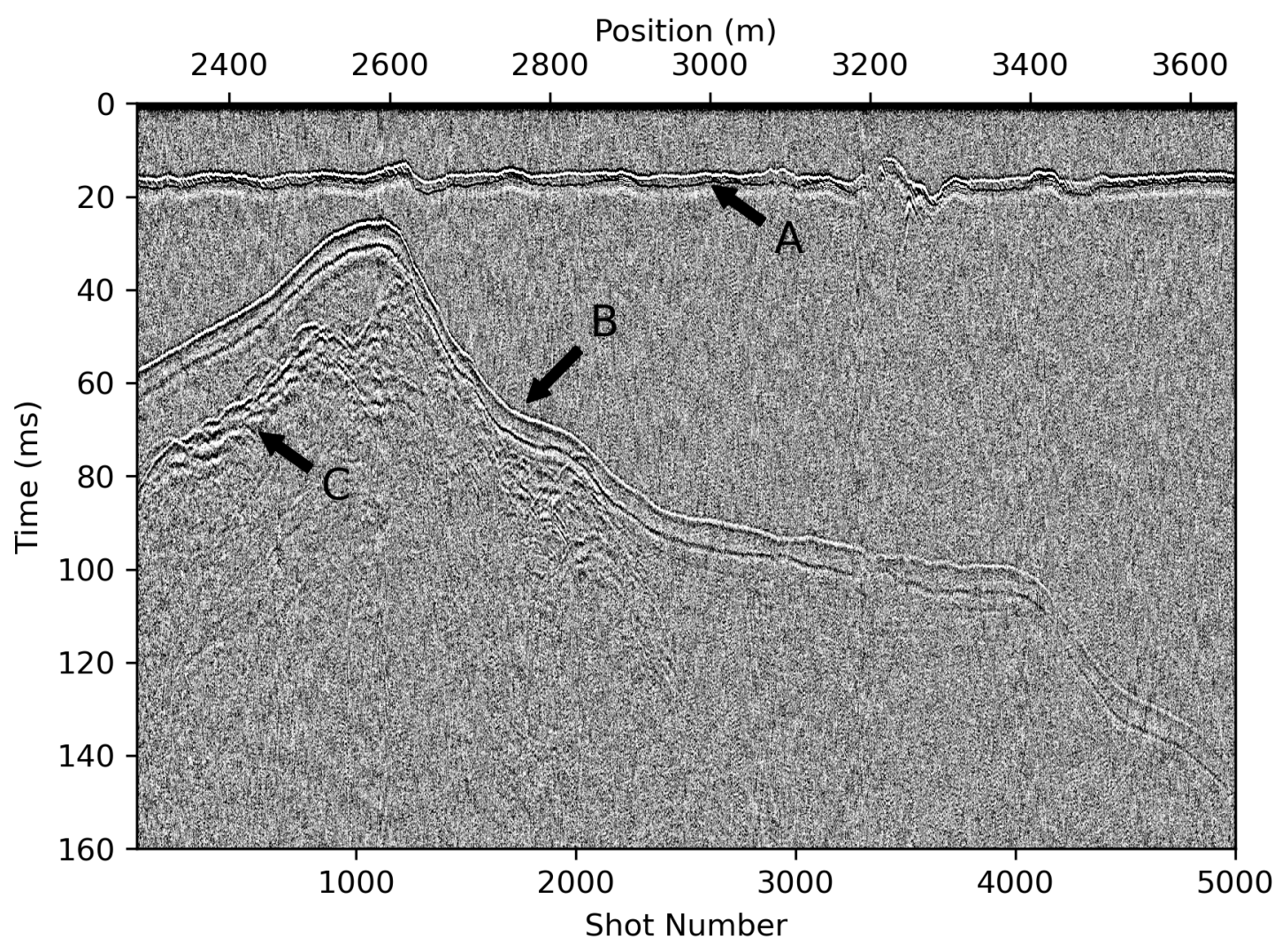

Figure 4: A common-channel seismic gather recorded by a towed single-channel streamer of $7 \mathrm{~m}$ hydrophone array (24 elements). The average shotpoint interval is $0.275 \mathrm{~m}$. The direct wave (A) and the reflections from the seafloor (B) and subsurface structures (C) are presented.

- This non-peer reviewed preprint submitted to EarthArXiv was submitted to Geophysics journal for peer review. 

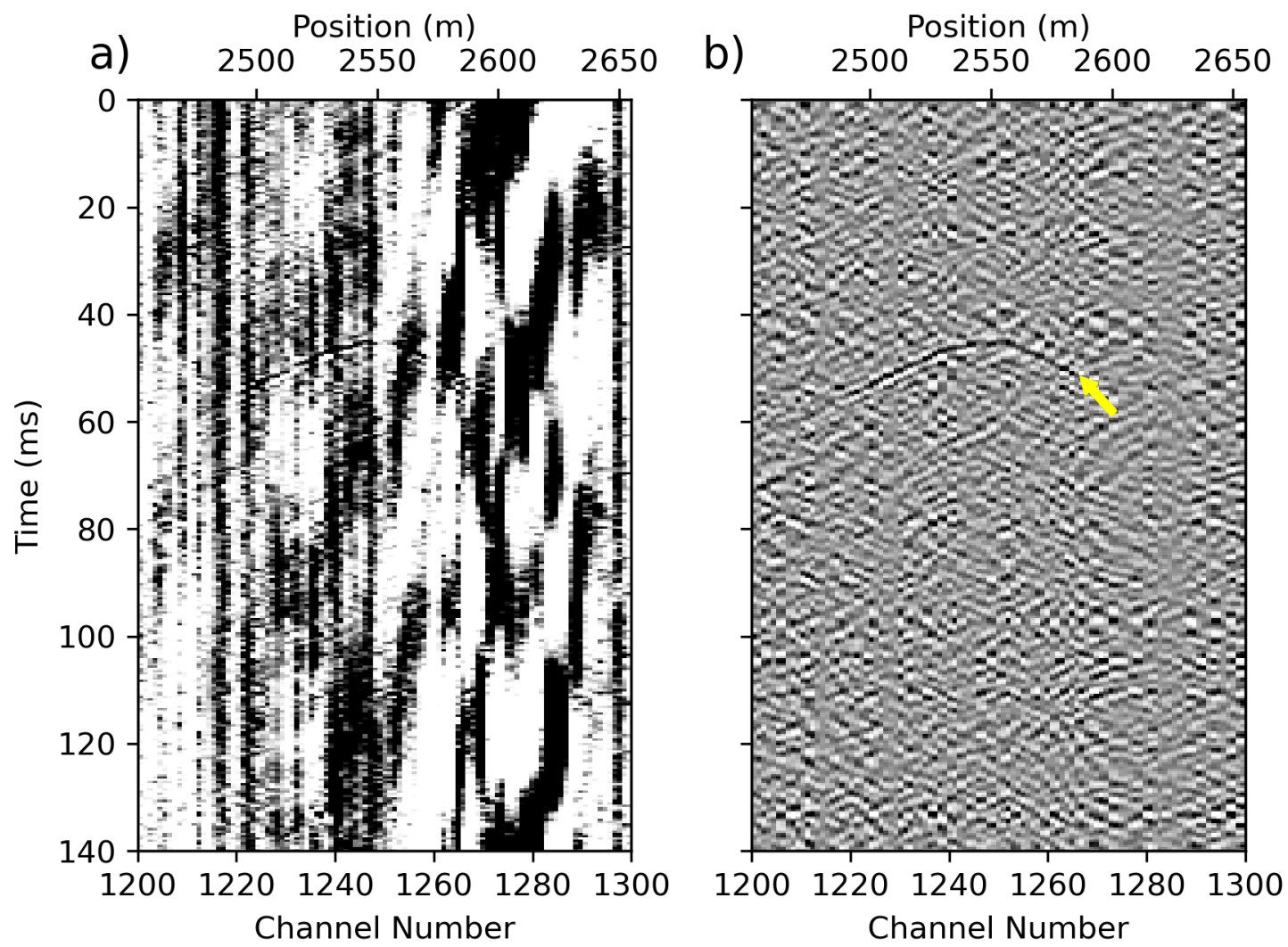

Figure 5: A shot profile (shot number 951) of multi-channel DAS seismic records: (a) raw data, and (b) data after applying a band-pass filter of $160-600 \mathrm{~Hz}$ for illustration. The direct wave from source to the receivers on the seafloor is the hyperbola in the shot profile as indicated by the yellow arrow. However, the underlying subsurface reflections are hardly observed.

- This non-peer reviewed preprint submitted to EarthArXiv was submitted to Geophysics journal for peer review. 


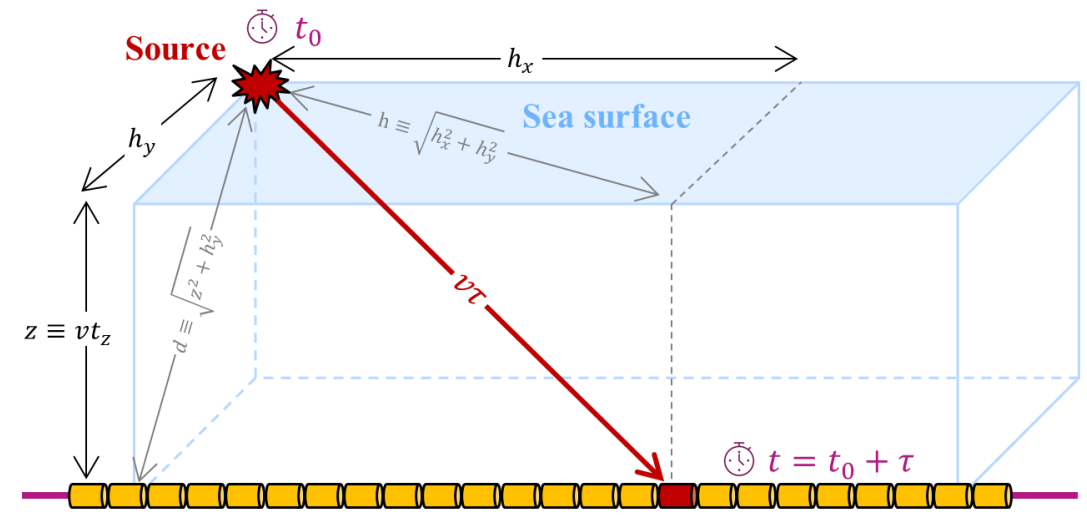

DAS (receivers)

Figure 6: DAS recording system and its seismic source, where $\tau$ is the traveltime that the wave directly propagates from source to a receiver at the inline offset $h_{x}$. At the receiver with zero inline offset $\left(h_{x}=0\right)$, the traveltime is shortest and equal to $\tau_{\left\{h_{x}=0\right\}}=\frac{d}{v}$, where $d$ is the distance between the source and DAS cable.

- This non-peer reviewed preprint submitted to EarthArXiv was submitted to Geophysics journal for peer review. 
a)

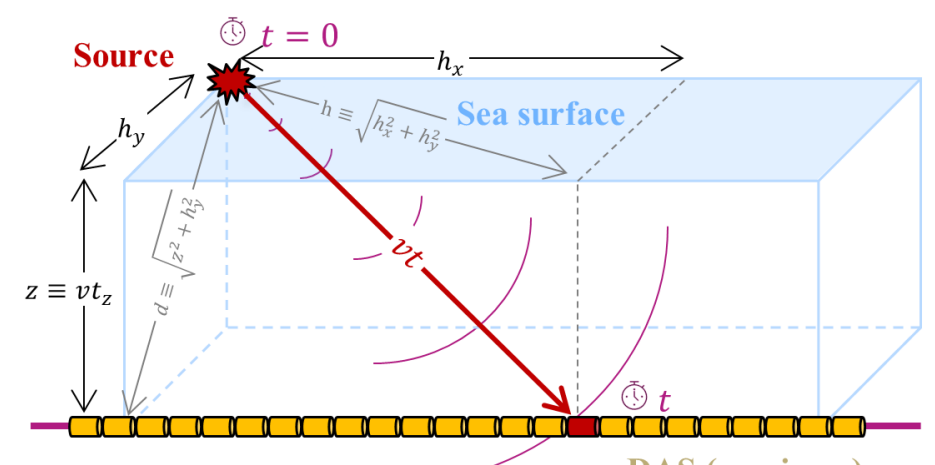

b)

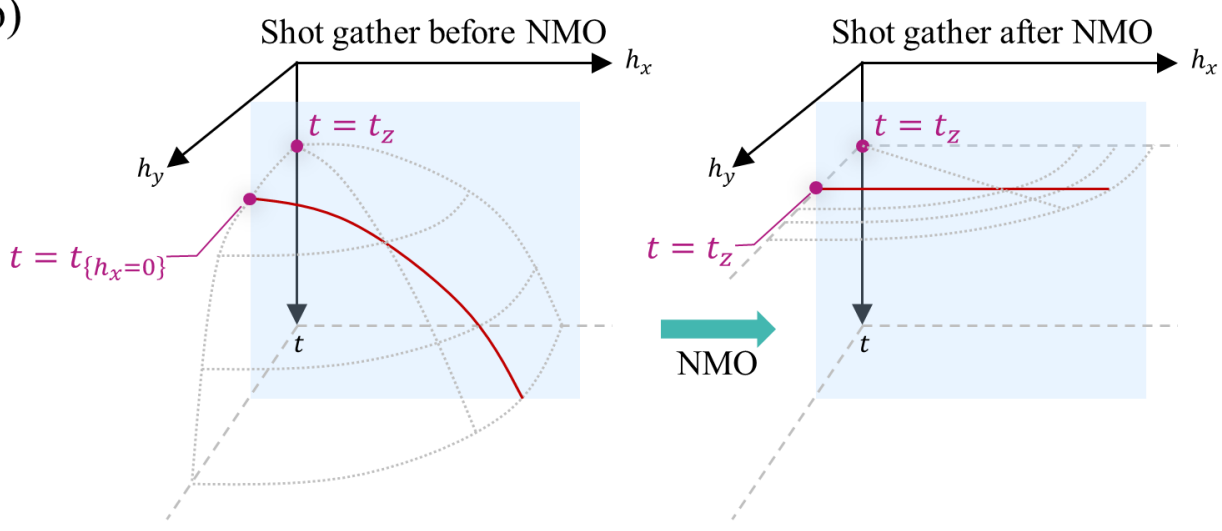

Figure 7: Description of NMO correction for the one-way traveltime of the direct wave in DAS recording system: (a) the geometry of the direct wave, and (b) the schematic plot of the direct wave in a shot gather before and after NMO correction. The traveltime of the direct wave is equal to the one-way traveltime along the vertical propagation distance to the seafloor.

- This non-peer reviewed preprint submitted to EarthArXiv was submitted to Geophysics journal for peer review. 


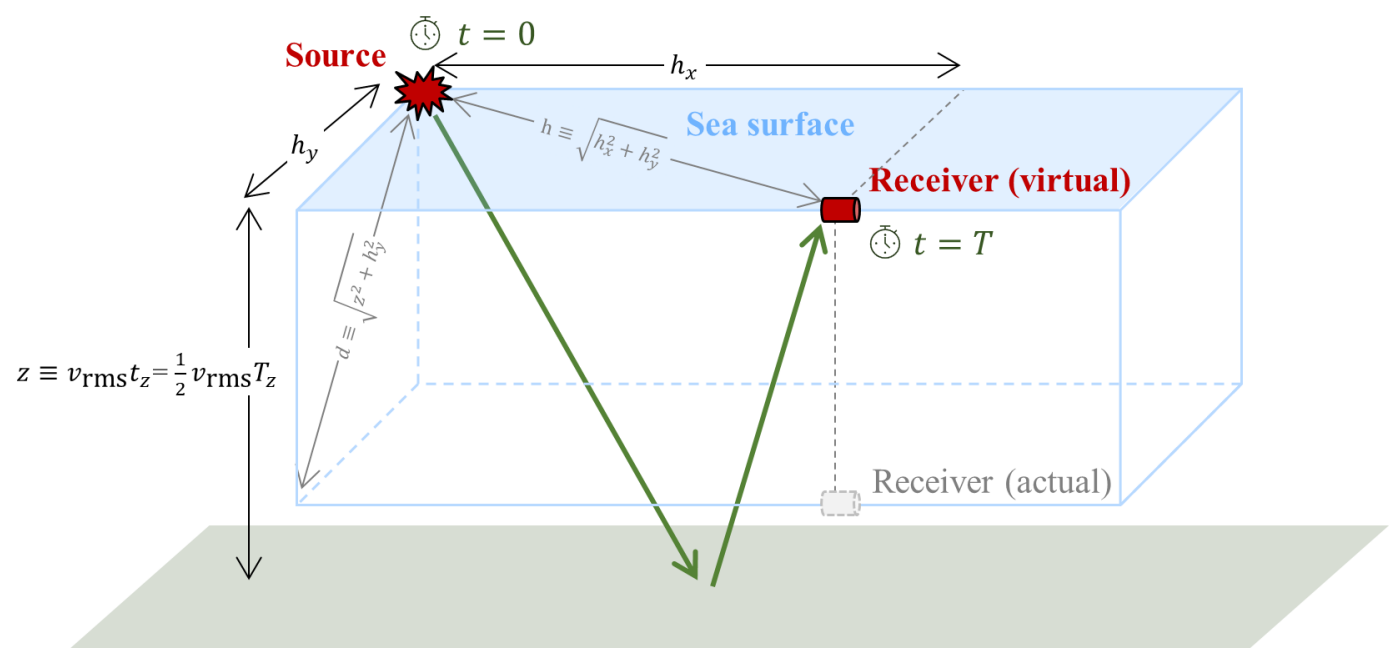

Figure 8: Description of NMO correction for two-way traveltime of the seismic reflection in DAS recording system.

- This non-peer reviewed preprint submitted to EarthArXiv was submitted to Geophysics journal for peer review. 


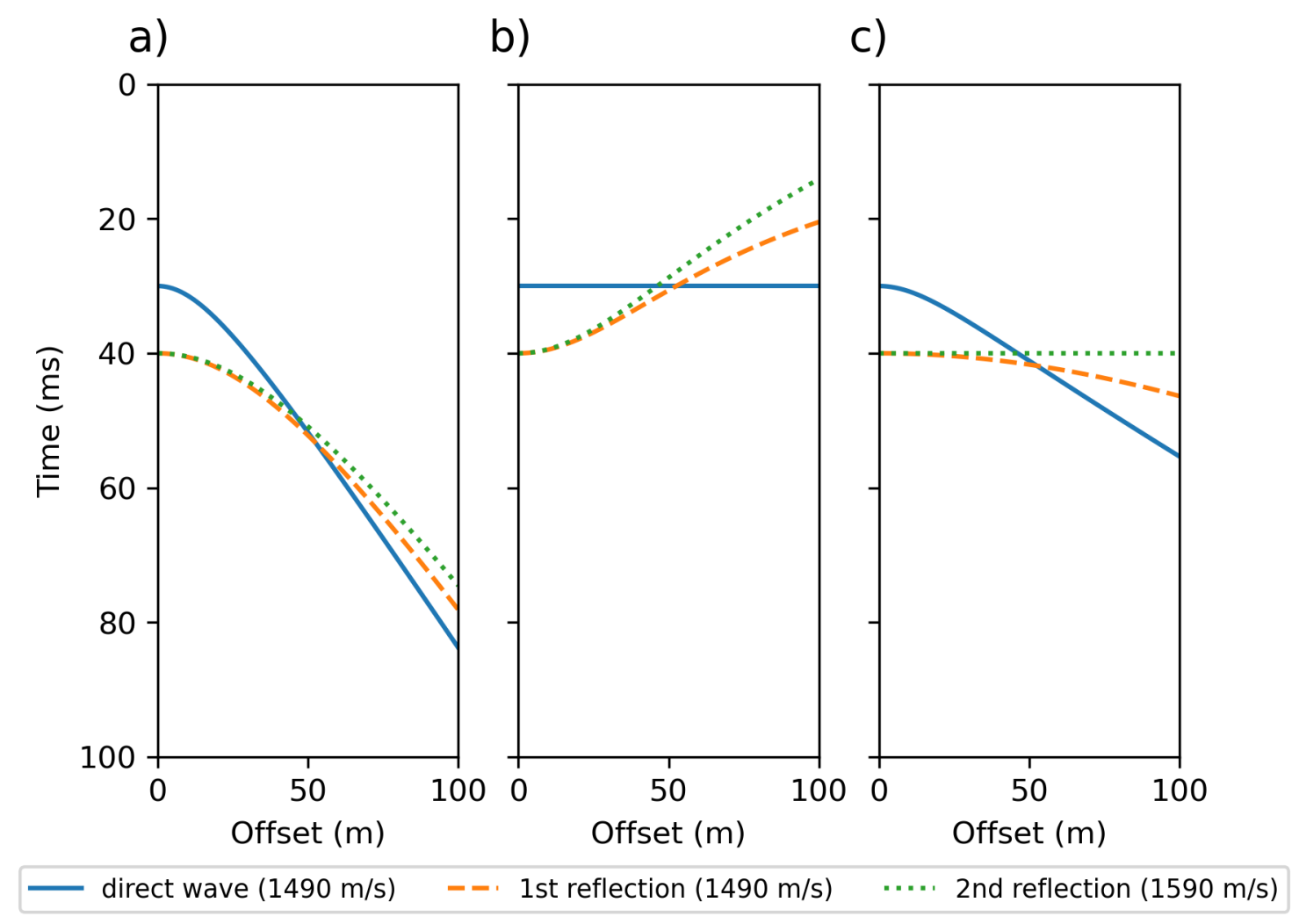

Figure 9: Illustration of different NMO correction methods for DAS recording on the 1D model comprising one seafloor reflector at $30 \mathrm{~ms}$ with $1490 \mathrm{~m} / \mathrm{s}$ RMS velocity, one subsurface reflector at $40 \mathrm{~ms}$ with $1490 \mathrm{~m} / \mathrm{s}$ RMS velocity, and one subsurface reflector at $40 \mathrm{~ms}$ with $1590 \mathrm{~m} / \mathrm{s}$ RMS velocity. The traveltime is referenced to the datum at sea surface. (a) Schematic shot profile of synthetic seafloor DAS data after redatuming the source and receivers to the sea surface. (b) The result of NMO correction for the direct wave using $1490 \mathrm{~m} / \mathrm{s}$ velocity. (c) The result of NMO correction for the subsurface reflection using $1590 \mathrm{~m} / \mathrm{s}$ velocity. Since the actual receivers are embedded to the seafloor reflector, three key seismic events are presented in the shot profile: (1) The solid blue curve is the direct wave arriving the DAS receivers on the seafloor; (2) The dashed orange curve is the wave reflected from the first subsurface reflector with $1490 \mathrm{~m} / \mathrm{s}$ RMS velocity; (3) The dotted 43 green curve is the wave reflected from the second reflector with $1590 \mathrm{~m} / \mathrm{s}$ RMS velocity. 


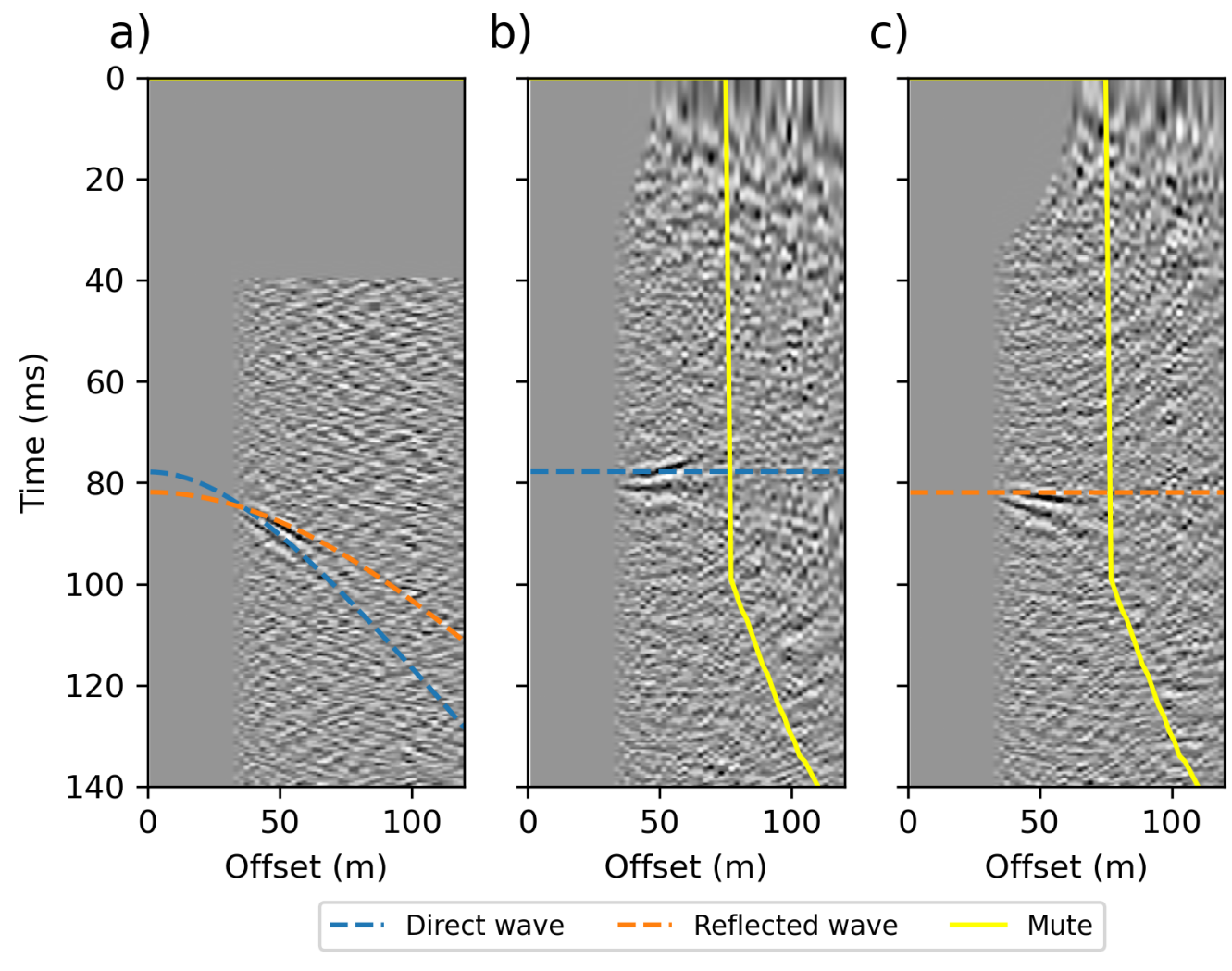

Figure 10: NMO corrections for the real DAS data set after redatuming to the sea surface and regularization. Supergathering the data from 21 shots around the shot number 2161, of which the position is approximately at $2877 \mathrm{~m}$ on the cable, is made to enhance $\mathrm{S} / \mathrm{N}$ for illustration: (a) A super shot gather sorted by regularized absolute horizontal offsets from source to the DAS receivers. (b) The result of NMO correction for direct wave. (c) The result of NMO correction for reflected wave. The dashed blue line is the direct wave event and the dashed orange line is a key reflection event, which are estimated by the associated time-velocity picks. The solid yellow line is the external mute function to be applied before stacking the data along offset.

- This non-peer reviewed preprint submitted to EarthArXiv was submitted to Geophysics journal for peer review. 

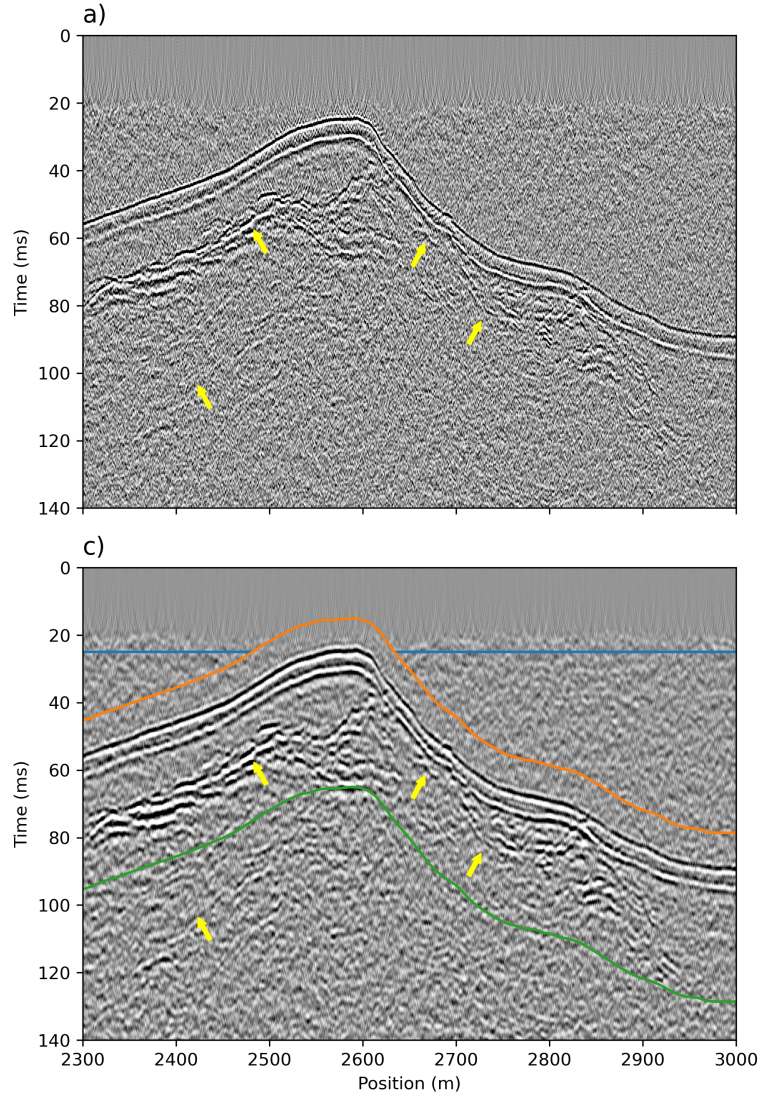

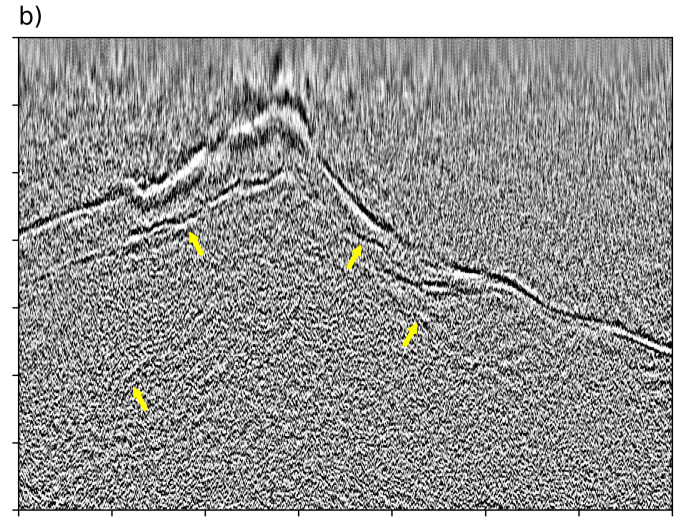

d)

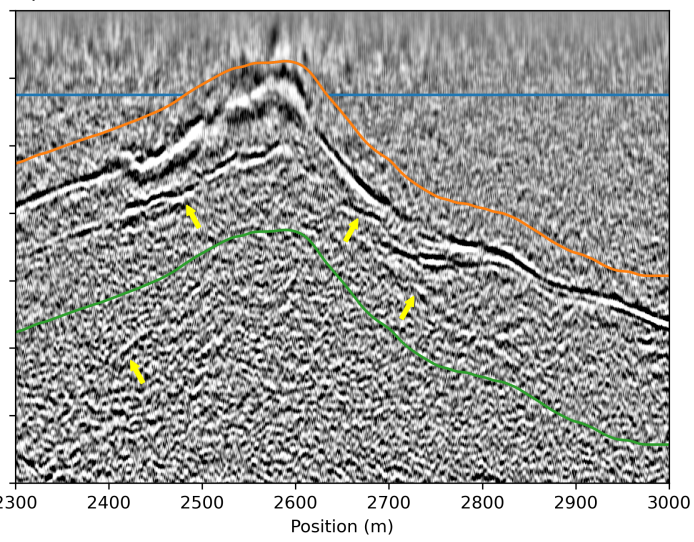

Figure 11: Poststack time migrated seismic images from different data sets: (a) the reference image from a towed single-channel streamer with a 24-element hydrophone array of $7 \mathrm{~m}$ active length, (b) the image from seabed DAS with $4 \mathrm{~m}$ gauge length, (c) the image of (a) with additional signal enhancement applied, and (d) the image of (b) with the same enhancement applied. The seismic events associated with the water bottom and subsurface reflections are presented in both images. Subsurface reflections in DAS image are highlighted by yellow arrows in comparison with the reference image. The horizontal axis is the distance along the cable. The horizons plotted in (c) and (d) define the signal and noise windows for computing the $\mathrm{S} / \mathrm{N}$ and spectrum in Figure 14. Signal window is defined between orange and green horizons, whereas noise window is defined between blue and orange horizons.

- This non-peer reviewed preprint submitted to EarthArXiv was submitted to 
a)

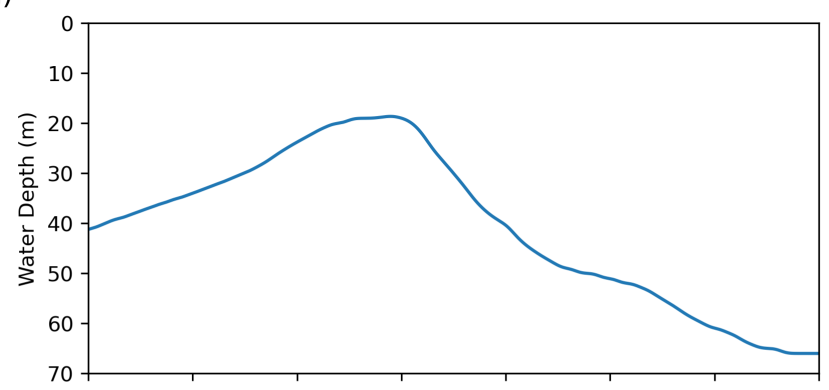

b)

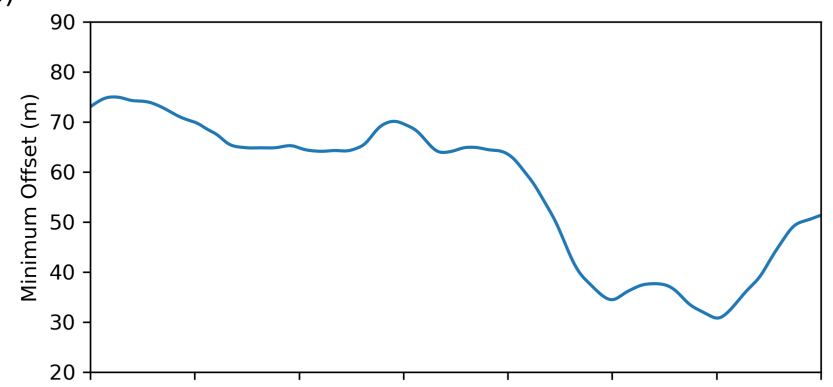

c)

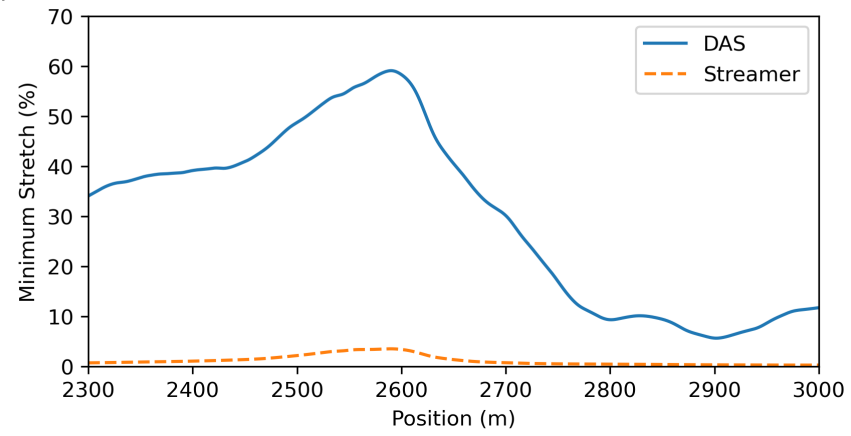

Figure 12: Plots of the following variables at different positions along DAS cable: a) the water depth; b) the crossline horizontal offset from source to the DAS cable, which is the minimum offset for each source position; and c) the minimum NMO stretch associated with the water bottom events in seismic data recorded by DAS (solid blue line) and towed streamer (dashed orange line). The minimum offset for towed streamer is assumed to be $10 \mathrm{~m}$ throughout the survey.

- This non-peer reviewed preprint submitted to EarthArXiv was submitted to Geophysics journal for peer review. 

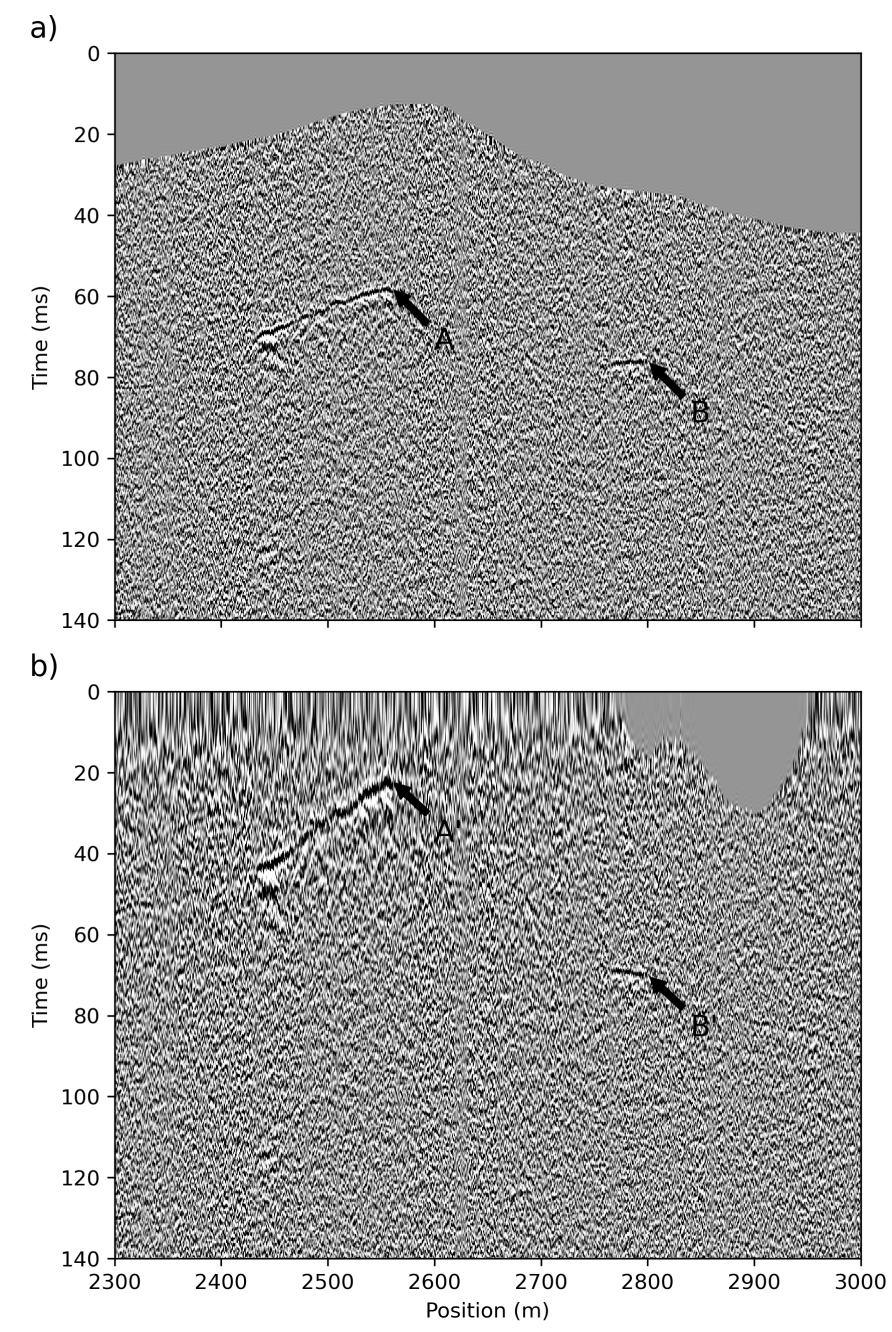

Figure 13: Illustration of NMO stretch effect on a near trace gather of DAS data where sources and receivers are redatumed to the sea surface: (a) near trace gather from the DAS data with common inline offset, and (b) the same gather after NMO correction for the direct wave is applied. Each trace of the near trace gather is formed by stacking the seismic traces with the inline offset less than $2 \mathrm{~m}$ from the corresponding shot gather. The absolute offset of each trace in the near trace gather is approximately equal to the crossline offset. The black arrows indicate the key events before and after NMO correction: event "A" has a large stretch effect after NMO, while event "B" only has a small effect from NMO stretch. The NMO stretch depends on the watter depth and crossline offset as illustrated in Figure 12. 
a)

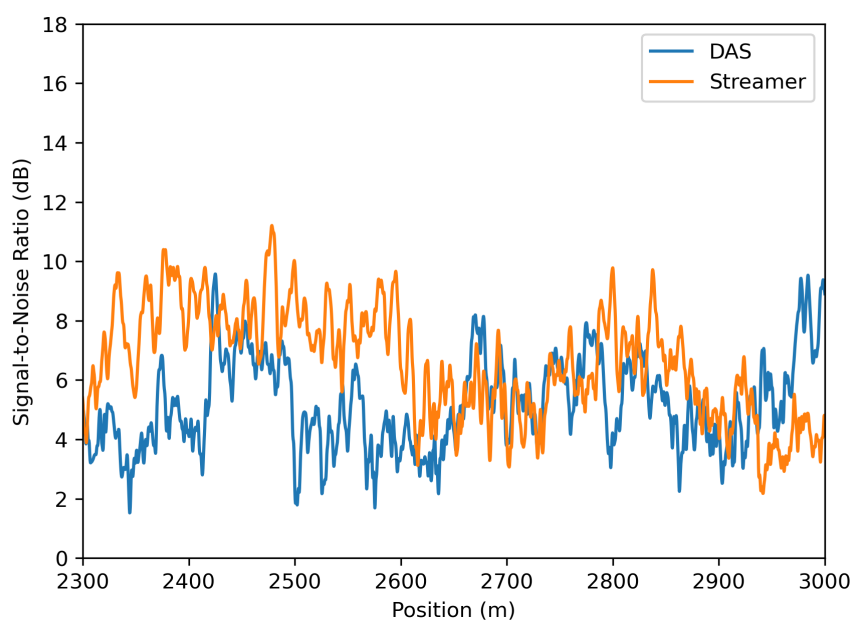

b)

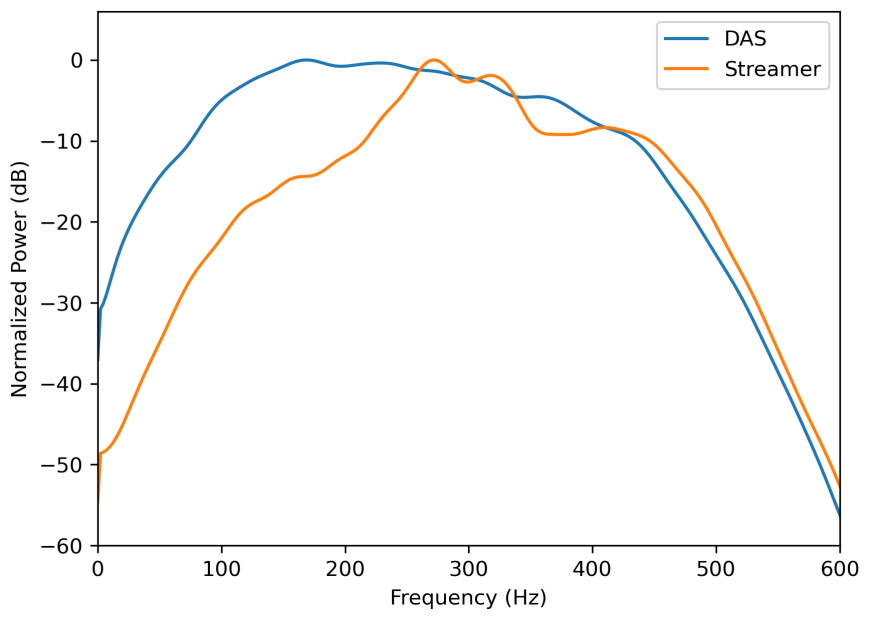

Figure 14: QC plots corresponding to the seismic images from DAS (blue) and towed streamer (orange) with additional signal enhancement applied as shown in Figure 11(c) and Figure 11(d): (a) S/N at different seismic traces, and (b) normalized amplitude spectrum within the signal window. Signal window is defined between orange and green horizons, whereas noise window is defined between blue and orange horizons in Figure 11.

- This non-peer reviewed preprint submitted to EarthArXiv was submitted to Geophysics journal for peer review. 